\title{
A structural perspective of CTD function
}

\author{
Anton Meinhart, ${ }^{1}$ Tomislav Kamenski, Sabine Hoeppner, Sonja Baumli, and Patrick Cramer ${ }^{2}$ \\ Gene Center, University of Munich (LMU), Department of Chemistry and Biochemistry, 81377 Munich, Germany
}

The C-terminal domain (CTD) of RNA polymerase II (Pol II) integrates nuclear events by binding proteins involved in mRNA biogenesis. CTD-binding proteins recognize a specific CTD phosphorylation pattern, which changes during the transcription cycle, due to the action of CTD-modifying enzymes. Structural and functional studies of CTD-binding and -modifying proteins now reveal some of the mechanisms underlying CTD function. Proteins recognize CTD phosphorylation patterns either directly, by contacting phosphorylated residues, or indirectly, without contact to the phosphate. The catalytic mechanisms of CTD kinases and phosphatases are known, but the basis for CTD specificity of these enzymes remains to be understood.

Over the last decade, a wealth of genetic and biochemical data revealed a physical and functional coupling between mRNA transcription by RNA polymerase II (Pol II), mRNA processing, and other nuclear events. Those coupling events are generally mediated by the C-terminal repeat domain (CTD) of the largest subunit of Pol II. The CTD is required for efficient capping, splicing, cleavage, and polyadenylation of mRNAs in vivo, and binds to RNA processing factors in vitro (McCracken et al. 1997b; Hirose and Manley 1998, 2000; Proudfoot et al. 2002). The binding of specific processing factors depends on the phosphorylation pattern of the CTD, which changes during the transcription cycle, and coordinates events of nuclear mRNA biogenesis (Dahmus 1995; Maniatis and Reed 2002; Palancade and Bensaude 2003; Proudfoot 2004; Sims et al. 2004; Zorio and Bentley 2004). Also coupled to mRNA transcription are chromatin remodeling and modification, DNA repair, mRNA packaging, RNA editing, and nuclear mRNA export (Reed 2003; Sims et al. 2004; Ares and Proudfoot 2005). A role of the CTD in these processes is just emerging. Here we review the structure, modification, and recognition of the CTD, from which insights into the molecular mechanisms of CTD-mediated coupling were obtained.

[Keywords: RNA polymerase II; gene transcription; nuclear coupling; Cterminal repeat domain; kinase; phosphatase]

${ }^{1}$ Present address: Max-Planck-Institute for Medical Research, Department of Biomolecular Mechanisms, Jahnstrasse 29, 69126 Heidelberg, Germany.

${ }^{2}$ Corresponding author.

E-MAIL cramer@LMB.uni-muenchen.de; FAX 49-89-2180-76999.

Article and publication are at http://www.genesdev.org/cgi/doi/10.1101/ gad.1318105.

\section{Free CTD structure}

The CTD forms a tail-like extension from the catalytic core of Pol II, and is flexibly linked to a region near the RNA exit pore of the enzyme (Fig. 1). In the crystal structures of yeast Pol II, the CTD is not visible due to mobility (Cramer et al. 2001; Armache et al. 2005). Also flexible is an 80-residue linker between the polymerase core and the CTD. The beginning of the linker forms an $\alpha$-helix that binds the polymerase subunit Rpb7, which together with Rpb4 constitutes a subcomplex that protrudes from the enzyme (Armache et al. 2005). The CTD consists of heptapeptide repeats of the consensus sequence Y1-S2-P3-T4-S5-P6-S7. The number of repeats depends on the species, and is 26 in yeast and 52 in human. At least eight repeats are required for yeast viability (Nonet et al. 1987; West and Corden 1995).

Current evidence suggests that the free CTD is largely flexible, although it shows some residual structure and a tendency to form $\beta$-turns. The CTD contains two SPXX motifs (S2-P3-T4-S5, S5-P6-S7-Y1), which were proposed to form $\beta$-turn structures stabilized by two hydrogen bonds (Suzuki 1989). NMR studies of a single CTD consensus repeat peptide revealed such $\beta$-turns for the S2P3-T4-S5 motif, but also unfolded forms (Harding 1992). NMR and circular dichroism of a CTD peptide with eight repeats showed a small population of $\beta$-turns at both SPXX motifs in water, which increased in trifluoroethanol, a hydrogen-bond-promoting solvent /Cagas and Corden 1995). Another study also detected a low population of turn structures, which strongly increased with single amino acid mutations (Dobbins et al. 1996). A further study of an eight-repeat CTD peptide detected a content of $15 \%$ polyproline helix, and below $10 \%$ $\beta$-turn structure in water, which increases to $75 \%$ in 90\% trifluoroethanol (Bienkiewicz et al. 2000). Cyclic model peptides contain a larger content of $\beta$-turns than linear CTD peptides, with the turn at S2-P3-T4-S5 being more stable than at S5-P6-S7-Y1 (Kumaki et al. 2001). Recent studies of a two-repeat CTD peptide with a central phosphorylated S2 (pS2) residue, however, revealed a dynamic disordered ensemble (Noble et al. 2005). The largely disordered nature of the free CTD apparently allows for many different interactions with target proteins via an induced fit mechanism.

In an extended $\beta$-strand conformation, the length of the yeast CTD and linker would be $\sim 650 \AA$ and $250 \AA$, respectively (Fig. 1; Cramer et al. 2001). Thus, the CTD 
Figure 1. Elongating RNA polymerase II and size of the CTD. The complete 12-subunit yeast Pol II elongation complex structure (Kettenberger et al. 2004; Armache et al. 2005) is shown as a ribbon diagram with the subunits in different colors. DNA is in blue and RNA is in red. DNA and RNA outside the polymerase have been extrapolated or

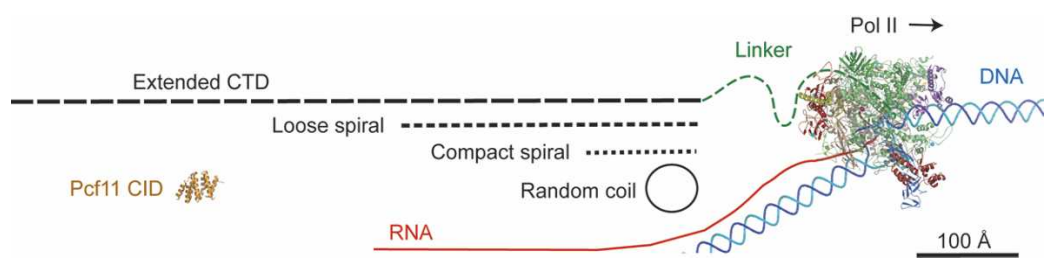
modeled. The relative sizes of the yeast Pol II largest subunit linker region and the CTD are indicated in green and black, respectively. The CTD is depicted in four putative states, fully extended, as a loose or compact $\beta$-spiral, and as a random coil. For size comparison, the Pcf11 CID is depicted in gold (Meinhart and Cramer 2004).

could in principle reach anywhere on the surface of Pol II, which is $\sim 150 \AA$ in diameter. The CTD is, however, most likely compact, at least in its unphosphorylated state. Electron micrographs of Pol II revealed a weak density that was attributed to the CTD and measured only $\sim 100 \AA$ (Meredith et al. 1996). Pol II crystals contain a limited space adjacent to the linker that could harbor a compact CTD (Cramer et al. 2001). Electrophoretic analysis, gel filtration, and sucrose gradients revealed that phosphorylation of the CTD results in a far more extended and more protease-sensitive structure (Laybourn and Dahmus 1989; Zhang and Corden 1991). One possible form of a compact CTD is a random coil (Cramer et al. 2001). Alternatively, unusual " $\beta$-spiral" models were proposed that account for the equivalence of CTD repeats in NMR studies (Matsushima et al. 1990; Suzuki 1990; Cagas and Corden 1995). One type of $\beta$-spiral consists of a series of staggered overlapping $\beta$-turns, two per CTD repeat, and an early model of this type had a length of $280 \AA$ A for the yeast CTD ("loose spiral") (Fig. 1; Cagas and Corden 1995). A more compact $\beta$-spiral, only $100 \AA$ long, and assuming only one $\beta$-turn per repeat, was suggested based on a crystal structure of a CTD peptide bound to a CTD-binding domain ("compact spi-

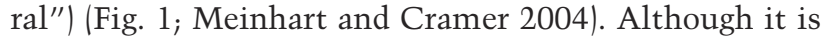
unlikely that the CTD adopts a uniform repetitive conformation, portions of the CTD may adopt a spiral form, leading to an overall compaction. Upon extensive phosphorylation, compact forms of the CTD would become more extended due to charge repulsions.

\section{CTD modification}

There are five potential phosphorylation sites in a CTD consensus repeat (Y1, S2, T4, S5, and S7) (Fig. 2A). CTD phosphorylation, however, occurs mainly at residues S2 and S5 (Corden et al. 1985; Zhang and Corden 1991), and these two serine positions are not equivalent in function (West and Corden 1995; Yuryev and Corden 1996). Phosphorylation at S2 and S5 gives rise to four different phosphorylation states of a CTD repeat (unphosphorylated, phosphorylated at S2, phosphorylated at S5, phosphorylated at S2 and S5). The phosphorylated form of Pol II carries, on average, one phosphate per repeat (Payne and Dahmus 1993). The phosphorylation state of the CTD is generally believed to be the result of the balanced action of site-specific CTD kinases and phosphatases. The phosphorylation pattern changes during the transcription cycle, resulting in recruitment of specific RNA-processing factors. S5 phosphorylation occurs in promoterproximal regions, and leads to recruitment of the capping enzyme (Cho et al. 1997; McCracken et al. 1997a; Ho et al. 1998; Komarnitsky et al. 2000). S2 phosphorylation predominates in regions that are more distal from the promoter, and triggers binding of the $3^{\prime}$-RNA processing machinery (Komarnitsky et al. 2000; E.J. Cho et al. 2001). Thus there may be a "CTD code" that specifies the position of Pol II within the transcription cycle (Buratowski 2003).

A CTD code could consist of 16 different states of the CTD repeat, which result from the combination of four different phosphorylation states with four possible proline configurations (residues P3 and P6 can each be in cis or trans conformation) (Buratowski 2003). The situation, however, becomes much more complicated when one considers how a CTD code may be read, in other words, how the different states of the CTD are recognized by proteins. First, proteins can bind more or less than one CTD repeat, and thus a single repeat is generally not the functional unit of the CTD. Indeed, genetics indicates that heptapeptide pairs are the functional units of the CTD (Stiller and Cook 2004). Second, it is unclear how the action of prolyl isomerases on the CTD can change specificity for CTD-binding proteins, since these enzymes only accelerate cis/trans isomerization of proline residues, in contrast to kinases, which set a phosphate mark in the CTD, or phosphatases, which remove the phosphate mark. However, the prolyl isomerase Pin1 can influence the phosphorylation pattern of the CTD in vitro, and the hypophosphorylated Pol II accumulates in pin $1^{-/-}$cells (Xu et al. 2003). Third, the CTD code may be extended by phosphorylation at residue Y1 (Baskaran et al. 1993, 1997), and by possible CTD glycosylation (Kelly et al. 1993). Fourth, the 52nd repeat in the human CTD contains a phosphorylated casein kinase II site (Chapman et al. 2004). Finally, a short motif at the C terminus of the CTD, outside of the repeats, is also important for the stability and the function of the CTD (Fong et al. 2003; Chapman et al. 2004).

\section{Architecture of CTD-binding domains}

The guanylyltransferase domain of the capping enzyme subunit Cgtl binds the phosphorylated CTD (Cho et al. 


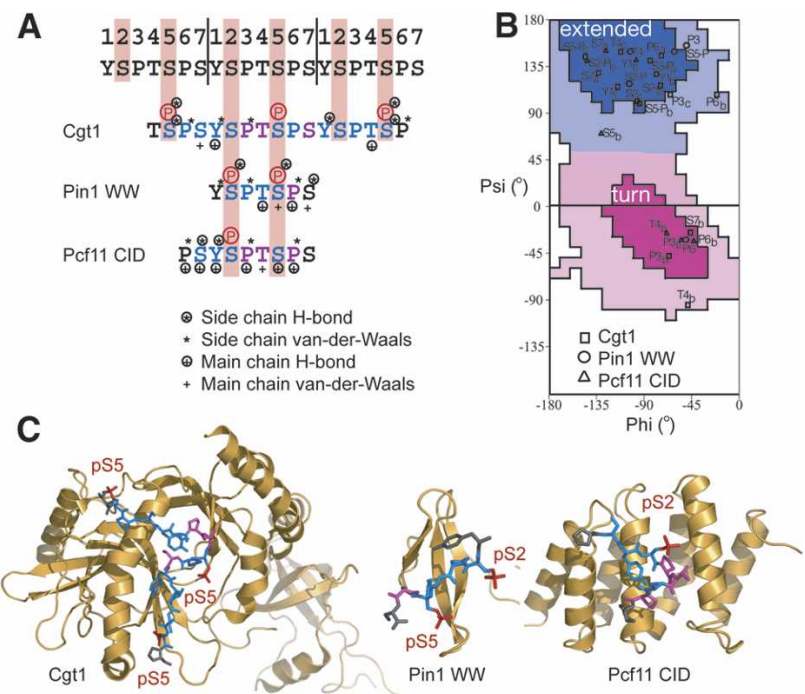

Figure 2. CTD structure and recognition. (A) CTD primary structure and protein contacts. On the top, three CTD consensus repeats are shown with the phosphorylation sites S2 and S5 highlighted in light red. The sequences of the CTD phosphopeptides in the known CTD structures in complex with Cgt1 (Fabrega et al. 2003), Pin1 WW (Verdecia et al. 2000), and Pcf11 CID (Meinhart and Cramer 2004) are depicted. Residues in an extended and turn conformation are in blue and magenta, respectively. Phosphate groups are shown as a circled red P. Contacts within $4 \AA$ distance of CTD residues to side-chain and main-chain atoms of the protein are indicated with stars and crosses, respectively (Collaborative Computational Project, Number 4, 1994). Circling indicates hydrogen bonds (within 3.5 $\AA$ distance). (B) Ramachandran plot for CTD peptides in the three complex structures (Laskowski et al. 1993). Regions for $\beta$-strand (extended) and for $\alpha$-helical (turn) conformations are highlighted in blue and magenta, respectively. CTD residues in the structures with Cgt1 (Fabrega et al. 2003), Pin1 WW (Verdecia et al. 2000), and Pcf11 CID (Meinhart and Cramer 2004) are indicated by squares, circles, and triangles, respectively, and are labeled as in the original papers. $(C)$ Structures of CTD complexes with Cgt1 (Fabrega et al. 2003), Pin1 WW (Verdecia et al. 2000), and Pcf11 CID (Meinhart and Cramer 2004). The CTD peptides are shown as atomic models and are colored according to $A$ and $B$. Phosphate groups are in red. The proteins are shown as ribbon models in gold.

1997; McCracken et al. 1997a). The Cgt1 domain structure reveals a mixed $\alpha / \beta$-fold (Fig. 2; Fabrega et al. 2003). Other RNA-processing factors bind to the phosphorylated CTD via compact domains devoted only to CTD binding, including WW domains, FF domains, and CTDinteracting domains (CIDs) (Fig. 2). These domain families differ in their structure and CTD-binding properties (Fig. 2). WW domains are 40-residue domains with two signature tryptophan residues spaced by 20-22 amino acids (Bork and Sudol 1994). Based on their binding specificity, WW domains can be divided into five subgroups. Subgroup IV WW domains are specific for phosphoserine-proline $(\mathrm{pSP})$ motifs, which occur twice in the consensus CTD repeat. CTD-binding WW domains are found in the prolyl isomerases Pin1/Ess1 (Morris et al. 1999), and in the splicing factor Prp40 (Morris and
Greenleaf 2000). The N-terminal WW domain of Pin1/ Ess1 forms a three-stranded antiparallel twisted $\beta$-sheet (Ranganathan et al. 1997; Verdecia et al. 2000; Li et al. 2005). FF domains comprise two conserved phenylalanine residues. Multiple copies of FF domains that bind the phosphorylated CTD are found in the elongation factor CA150 (Carty et al. 2000) and the splicing factor Prp40 (Morris and Greenleaf 2000). The FF domains in Prp40 are homologous to an FF domain in FBP 11, which interacts with phosphorylated CTD peptides in vitro (Allen et al. 2002). The structure of the FF domain of FBP11 consists of a three-helix bundle with a $3_{10}$-helix inserted into the loop between the second and third helix (Allen et al. 2002). CID domains are found in the poly(A)dependent 3 '-RNA processing factor Pcf11 (Barilla et al. 2001), in the poly(A)-independent 3 '-processing factor Nrd1 (Steinmetz et al. 2001), in the serine/arginine-richlike factors SCAF4 and SCAF8 (Yuryev et al. 1996; Patturajan et al. 1998b), and in Rtt103, a factor involved in transcription termination (Kim et al. 2004b). The CID domain of Pcf11 consists of eight $\alpha$-helices in a righthanded superhelical arrangement (Fig. 2; Meinhart and Cramer 2004).

Several other CTD-binding folds exist. BRCT domains can bind the phosphorylated CTD (see CTD phosphatases). The $3^{\prime}$-RNA processing factor Rna14 is predicted to contain HEAT repeats, and its fold might resemble that of CID domains. In contrast, the CTD-binding cleavage and polyadenylation factor Yhh1 is predicted to contain $\beta$-propeller repeats (Dichtl et al. 2002b). Another small CID was discovered in the histone methyltransferase Set2 (Phatnani et al. 2004; Kizer et al. 2005), and is predicted to be $\alpha$-helical.

\section{CTD recognition}

Our current understanding of the stereochemical basis of CTD recognition by CTD-binding proteins is based on three-dimensional structures of differently phosphorylated CTD peptides bound to phospho-CTD-binding domains (Fig. 2): a S5-phosphorylated CTD peptide bound to the guanylyltransferase domain of Cgt1 (Fabrega et al. 2003), a doubly S2/S5-phoshorylated CTD peptide bound to the WW domain of Pin1 (Verdecia et al. 2000), and a S2-phosphorylated CTD peptide bound to the CID domain of Pcf11 (Meinhart and Cramer 2004). In all structures, the CTD peptide binds to a conserved groove of the domain, suggesting that the same interactions occur with other family members.

The structure of the S5-phosphorylated CTD peptide bound to Cgt1 revealed a largely extended CTD conformation (Fabrega et al. 2003). Cgt1 can bind almost three CTD repeats. The central CTD repeat is partially looped out, forms a turn-like structure, and makes few interactions with the protein. The two flanking repeats are in an extended $\beta$-strand-like conformation (Fig. 2). Hydrophobic interactions involve the proline residues of the CTD, and the tyrosine residue $\mathrm{Y} 1$, which also forms a hydrogen bond with a Cgtl residue via its phenylic hydroxyl group. This interaction is incompatible with Y1 phos- 
phorylation. Cgt1 binds the phosphate groups of phosphoserine-5 (pS5) residues in the two extended flanking repeats, but not the one in the central repeat. An important implication of this structure is that these domains may bind two remote stretches of the CTD ("bivalent" or "bipartite" recognition), thereby looping out the intervening sequence. Such looping could facilitate formation of turned structures within the CTD, as observed for free cyclic CTD peptides (Kumaki et al. 2001). Looped structures induced by CTD binding of one factor could be recognized by another CTD-binding factor, possibly contributing to sequential factor binding.

The structure of a doubly S2/S5-phosphorylated CTD peptide bound to the Pin 1 WW domain also revealed an extended CTD conformation (Verdecia et al. 2000). The P3-T4-pS5-P6 motif of the CTD peptide interacts with the protein. The two prolines are involved in van der Waals interactions with hydrophobic groups of Pin 1, and two hydrogen bonds are formed with the peptide backbone. The WW domain of Pin 1 binds the pS5 phosphate group with several hydrogen bonds, and one hydrogen bond is formed with the pS2 phosphate (Verdecia et al. 2000). In binding assays, the protein is not specific for S2 or S5 phosphorylation (Myers et al. 2001).

In the structure of a S2-phosphorylated CTD peptide bound to the CID domain of Pcf11, the CTD motif S2P3-T4-S5 forms a $\beta$-turn, whereas the flanking residues are in an extended conformation (Fig. 2; Meinhart and Cramer 2004). Hydrogen bonds are formed between the CTD and the CID domain, and CTD residues Y1 and P3 bind to hydrophobic patches. The phenylic hydroxyl of Y1 forms a hydrogen bond with a conserved aspartate that is required for normal yeast growth (Sadowski et al. 2003). The side chain of CTD residue S5 is exposed, consistent with the observation that S5 phosphorylation does not influence binding of the CID domain in SCAF8 (Patturajan et al. 1998b). The pS2 phosphate group does also not contact the CID domain, consistent with the ability of Pcf11 to bind the unphosphorylated CTD. However, S2 phosphorylation strongly enhances the affinity of the CTD for the CID domain (Licatalosi et al. 2002), suggesting that the pS2 phosphate group is recognized indirectly (Meinhart and Cramer 2004). The pS2 phosphate forms an intramolecular hydrogen bond with the T4 side chain, which was proposed to stabilize the $\beta$-turn conformation (Meinhart and Cramer 2004).

A recent NMR study of the CTD-Pcf11 interaction (Noble et al. 2005) generally confirmed the crystallographic results (Meinhart and Cramer 2004), and found additionally that the pS2-T4 hydrogen bond in the CTDCID complex is not present in the free CTD, suggesting that the CTD turn conformation observed in the complex results from induced fit. Although the apparent indirect recognition of the CTD pS2 phosphate is not fully understood, an advantage of such indirect recognition was suggested (Meinhart and Cramer 2004). Exposure of a CTD phosphate group could be important for its accessibility to a phosphatase, which could remove the phosphate, lower the binding affinity, and trigger CTD dissociation from CTD-binding domains (Meinhart and Cra- mer 2004). Although sequence conservation suggests that all CIDs share the same fold, there are apparently differences in the details of CTD recognition by CID domains. The CID domain in the recently characterized factor Rtt103, which is involved in transcription termination (Kim et al. 2004a), contains a CTD-binding pocket that differs in several amino acid positions from that of Pcf11.

Taken together, three different CTD conformations are observed in the three known CTD peptide-protein complex structures, reflecting the structurally versatile nature of the CTD and indicating that an induced fit to the target surface plays an important role in CTD recognition. Comparison of the structures and CTD conformations suggests that there is no simple structural basis for a possible CTD code. However, a few underlying principles of CTD recognition can be extracted. CTD peptides adopt extended $\beta$-strand-like, or $\beta$-turn conformations (Fig. 2B). In all three structures, the P3 side chain docks into a hydrophobic pocket of the target protein. In two structures (CID, Cgt1), the Y1 side chain is bound through hydrophobic interactions and via a hydrogen bond to its phenylic hydroxyl, incompatible with Y1 phosphorylation. Phosphorylated serines can be recognized directly, by interactions with the phosphate group, or indirectly, by a mechanism that is not clear yet. In all complex structures, prolines $\mathrm{P} 3$ and $\mathrm{P} 6$ are in trans conformation, and their isomerization to cis would likely impair binding. Since a CTD peptide exists as a mixture of cis and trans populations in solution (Noble et al. 2005), the target domains apparently select the trans isomer.

\section{CTD-Mediator interaction}

Transcription initiation involves the interaction of the unphosphorylated CTD with the Mediator complex, the central multiprotein coactivator that transmits signals from activators and repressors to Pol II (Malik and Roeder 2000; Myers and Kornberg 2000; Bjorklund and Gustafsson 2004). In yeast, the CTD is required for the formation of a stable yeast Pol II-Mediator complex (Myers et al. 1998; Asturias et al. 1999). Antibodies against the unphosphorylated CTD displace Mediator from Pol II (Svejstrup et al. 1997). The CTD-Mediator interaction is required for Mediator function, since yeast Mediator cannot stimulate transcription by a CTD-less Pol II (Myers et al. 1998). The phosphorylated CTD does not associate with Mediator (Svejstrup et al. 1997), and CTD phosphorylation during transcription initiation apparently breaks the Pol II-Mediator interaction, resulting in an elongating polymerase and a scaffold complex that remains at the promoter (Liu et al. 2004). Consistent with the conservation of Mediator, mouse and Drosophila Mediator also bind the CTD (Jiang et al. 1998; Park et al. 2001). The human Mediator-like complex CRSP also interacts with the CTD and adopts a specific CTD-bound conformation (Naar et al. 2002). Addition of recombinant CTD inhibits CRSP-dependent transcription activation. 
The yeast Mediator comprises up to 25 subunits; 11 are essential and 22 are at least partially conserved in sequence among eukaryotes (Boube et al. 2002; Bourbon et al. 2004). Nine of the Mediator subunits were identified in a genetic screen for suppressors of CTD truncation mutants (Thompson et al. 1993; Hengartner et al. 1995). According to biochemical and genetic studies, Mediator consists of three distinct submodules (Kang et al. 2001), which may correspond to density lobes observed by electron microscopy, termed head, middle, and tail, respectively (Dotson et al. 2000). The CTD may bind between the head and middle modules, since recombinant head and middle modules independently bind to the CTD (Kang et al. 2001). The middle module is the most conserved module and includes the MED7/MED21 heterodimer. The recent structure of the MED7/MED21 heterodimer revealed a novel, very extended helical fold, and a flexible hinge (Baumli et al. 2005) that may partially account for changes in the overall Mediator structure upon binding to Pol II (Asturias et al. 1999; Davis et al. 2002; Naar et al. 2002) or to activators (Taatjes et al. 2002).

Larger isoforms of Mediator include a module that contains a CTD kinase, and can act independently of the CTD. For example, the Mediator-like complex SMCC from human cells does not require the CTD for activation (Gu et al. 1999). The repressive function of the Mediator-like human complex NAT is also independent of the CTD (Sun et al. 1998). The large inactive human Mediator ARC-L does not interact with the CTD (Naar et al. 2002). Consistent with these observations, electron microscopic images of the yeast Pol II-Mediator complex suggest that the CTD is not the sole point of contact between Mediator and the polymerase, but that there are multiple interaction sites (Asturias et al. 1999). In addition, Mediator binds to several general transcription factors involved in initiation (Kang et al. 2001; Park et al. 2001).

\section{CTD kinases}

The CTD is phosphorylated by the regulated action of cyclin-dependent kinases (CDKs). CDKs associate with specific cyclins and play central roles in transcription and cell cycle regulation (Dynlacht 1997; Bregman et al. 2000; Murray 2004). The CTD is targeted by CDK7, CDK8, and CDK9, which generally associate with cyclins $\mathrm{H}, \mathrm{C}$, and $\mathrm{T}$, respectively. The abundance of these cyclins does not fluctuate during the cell cycle (Tassan et al. 1994; Rickert et al. 1996). In addition to CDK7, CDK8, and CDK9, CDK11 was recently implicated in the coordination of transcription with RNA processing (Hu et al. 2003). Whereas all CDKs show a high degree of conservation (Russo et al. 1996; Tarricone et al. 2001; Lolli et al. 2004), the cyclins are less conserved, and cyclins involved in transcription are only weakly related to classical cyclins involved in cell cycle regulation (Leopold and O'Farrell 1991; Lew et al. 1991).

The CDK7/cyclin $\mathrm{H}$ pair associates with the RING finger protein MAT1 to form the CDK-activating kinase
(CAK), which phosphorylates and activates other CDKs involved in cell cycle regulation (Harper and Elledge 1998; Kaldis 1999|. CAK also forms a subcomplex of the 10-subunit general transcription factor TFIIH, which phosphorylates the CTD at S5 during transcription initiation (Coin and Egly 1998). Electron microscopy showed that the CAK complex protrudes from the ringlike structure of TFIIH (Schultz et al. 2000). The yeast CDK7 homolog Kin28 is essential for viability, required for normal transcript levels in vivo, and is the primary kinase responsible for CTD phosphorylation during transcription initiation (Valay et al. 1995; Holstege et al. 1998; Komarnitsky et al. 2000; Schroeder et al. 2000; Liu et al. 2004). TFIIH kinase activity is enhanced by Mediator during initiation, driving the transition to elongation (Guidi et al. 2004), and facilitating recruitment of RNA processing factors (Rodriguez et al. 2000).

The CDK8/cyclin C pair (Srb10/Srb11 in yeast) associates with MED12 (Srb8) and MED13 (Srb9), to form a fourth module of the Mediator that is present in a subpopulation of Mediator complexes. This Mediator module phosphorylates the CTD, is conserved among eukaryotes, and is a target of signal transduction pathways (Liu et al. 2001; Borggrefe et al. 2002; Boube et al. 2002; Samuelsen et al. 2003). The CDK8/cyclin C pair is thought to be mainly implicated in transcriptional repression (Hengartner et al. 1998). One model for repression is that CDK8 phosphorylates the CTD prematurely, thereby preventing formation of a transcription initiation complex (Hengartner et al. 1998). Human CDK8/ cyclin $\mathrm{C}$ can also repress CDK7 activity by phosphorylating cyclin $\mathrm{H}$ (Akoulitchev et al. 2000). CDK8 further phosphorylates some gene-specific transcription factors, thereby decreasing their stability (Chi et al. 2001; Nelson et al. 2003). On the other hand, CDK8 can also have a positive effect on transcription. CDK8-dependent phosphorylation of the transcription factor Sip4 can stimulate transcription (Vincent et al. 2001). A positive effect also results from ATP-dependent dissociation of preinitiation complexes, triggered by CDK8 (Liu et al. 2004). CDK8-dependent phosphorylation of the Mediator subunit MED2 also has a positive effect on transcription (Hallberg et al. 2004).

The CDK9/cyclin T pair forms the core of the positive transcription elongation factor P-TEFb (Price 2000). The originally identified P-TEFb consists of CDK9 and one of the cyclin $\mathrm{T}$ isoforms T1, T2, or K (Peng et al. 1998). A larger $\mathrm{P}-\mathrm{TEFb}$ complex with reduced activity contains additionally the small nuclear RNA 7SK and the HEXIM protein (Nguyen et al. 2001; Yang et al. 2001; Michels et al. 2003; Yik et al. 2003). P-TEFb was isolated by its ability to overcome arrest of Pol II complexes during early elongation, a function that requires the CTD (Marshall and Price 1995; Marshall et al. 1996). P-TEFb phosphorylates the elongation factor DSIF on its Spt5 subunit and counteracts the negative effect of DSIF and its cofactor NELF during early elongation (Wada et al. 1998; Yamaguchi et al. 1998). There are two putative homologs of CDK9 in Saccharomyces cerevisiae, Ctk1 and Bur1 (Prelich and Winston 1993; Murray et al. 2001; Prelich 
2002; Guo and Stiller 2004). Ctk1 associates with its cyclin partner Ctk2 and a third subunit, Ctk3, to form the CTDK1 complex. Bur1 associates with the cyclin Bur2. Chromatin immunoprecipitation and genetic experiments suggest that Ctk1 and Burl play nonoverlapping roles in transcription elongation (Yao et al. 2000; E.J. Cho et al. 2001; Yao and Prelich 2002; Keogh et al. 2003). It is possible that in yeast Ctk1 and Bur1 phosphorylate the CTD and Spt5, respectively, which are both substrates of P-TEFb (Keogh et al. 2003). During stress response the CTD can also be phosphorylated at S5 by ERK kinases (Bonnet et al. 1999).

\section{Kinase structure and specificity}

The CDKs involved in CTD phosphorylation differ in their specificity toward the target serine residue. CDK7 and CDK8 phosphorylate S5, whereas CDK9 phosphorylates S2, although some conflicting reports exist (Table 1). CDK7 activity predominates during initiation, whereas CDK9 activity is important during elongation (Komarnitsky et al. 2000; E.J. Cho et al. 2001; Kim et al.
2002). CDK7 and CDK8, but not Bur1 or Ctk1, are stably associated with transcription initiation complexes (Liu et al. 2004). CDKs also differ in their processivity. CDK7 generates hyperphosphorylated CTD peptides, whereas CDK8 and CDK9 generate CTD peptides with fewer phosphorylated residues (Pinhero et al. 2004).

Crystal structures of free CDK7 (Lolli et al. 2004), cyclin H (Andersen et al. 1997), and cyclin C (S. Hoeppner, S. Baumli, and P. Cramer, unpubl.) are known (Fig. 3), but structures of CDK/cyclin complexes involved in transcription have not been determined. The structure of CDK7 is highly similar to that of other CDKs (Lolli et al. 2004). The active site is located between the two lobes of the CDK fold, and is partially covered by a loop, the so-called activation segment (Fig. 3). In contrast to the highly conserved CDK structure, cyclin structures show remarkable differences (Fig. 3). Two five-helix repeats form a conserved cyclin fold, but the length and exact orientation of the helices differ. In addition, cyclins differ strongly in the $\mathrm{N}$ - and $\mathrm{C}$-terminal regions flanking the cyclin fold. Whereas an $\mathrm{N}$-terminal helix in cell cycle cyclins is involved in CDK recognition, the correspond-

Table 1. Specificity of CTD kinases and phosphatases

\begin{tabular}{|c|c|c|c|}
\hline CTD-modifying enzyme & $\begin{array}{l}\text { S2 phosphorylation/ } \\
\text { dephosphorylation }\end{array}$ & $\begin{array}{l}\text { S5 phosphorylation/ } \\
\text { dephosphorylation }\end{array}$ & References \\
\hline \multicolumn{4}{|l|}{ CTD kinases } \\
\hline \multirow[t]{12}{*}{ CDK7 } & & + & Rickert et al. 1999 \\
\hline & & + & Trigon et al. 1998 \\
\hline & $(+)$ & & Dubois et al. 1997 \\
\hline & & & Patturajan et al. 1998a \\
\hline & & + & Zhou et al. 2000 \\
\hline & & + & Ramanathan et al. 2001 \\
\hline & & + & Sun et al. 1998 \\
\hline & + & + & Yamamoto et al. 2001 \\
\hline & & & Watanabe et al. 2000 \\
\hline & & + & Kim et al. 2002 \\
\hline & $(+)$ & + & Komarnitsky et al. 2000 \\
\hline & & + & Hengartner et al. 1998 \\
\hline \multirow[t]{5}{*}{ CDK8 } & + & + & Sun et al. 1998 \\
\hline & & + & Rickert et al. 1999 \\
\hline & & + & Ramanathan et al. 2001 \\
\hline & & + & Hengartner et al. 1998 \\
\hline & + & + & Borggrefe et al. 2002 \\
\hline \multirow[t]{5}{*}{ CDK9 } & + & $(+)$ & Komarnitsky et al. 2000 \\
\hline & + & $1+1$ & Zhou et al. 2000 \\
\hline & & + & Ramanathan et al. 1999, 2001 \\
\hline & + & & Shim et al. 2002 \\
\hline & + & & Kim et al. 2002 \\
\hline \multirow[t]{3}{*}{ Ctk1 } & + & & Patturajan et al. 1998a \\
\hline & + & & Cho et al. 2001a \\
\hline & + & + & Jones et al. 2004 \\
\hline Burl & & + & Murray et al. 2001 \\
\hline \multicolumn{4}{|l|}{ CTD phosphatases } \\
\hline Fcp1 (S. cerevisiae) & + & & Cho et al. 2001a \\
\hline Fcpl (S. cerevisiae) & & + & Kong et al. 2005 \\
\hline Fcpl (S. pombe) & + & & Hausmann and Shuman 2002 \\
\hline Fcp1 (human) & + & + & Lin et al. $2002 \mathrm{a}$ \\
\hline Scp1 & $(+)$ & + & Yeo et al. 2003 \\
\hline Ssu72 & & + & Krishnamurthy et al. 2004 \\
\hline CPLs & & + & Koiwa et al. 2004 \\
\hline
\end{tabular}



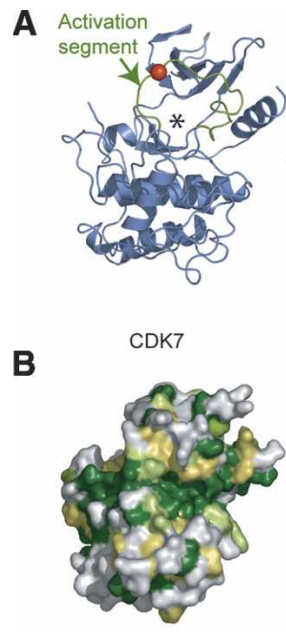
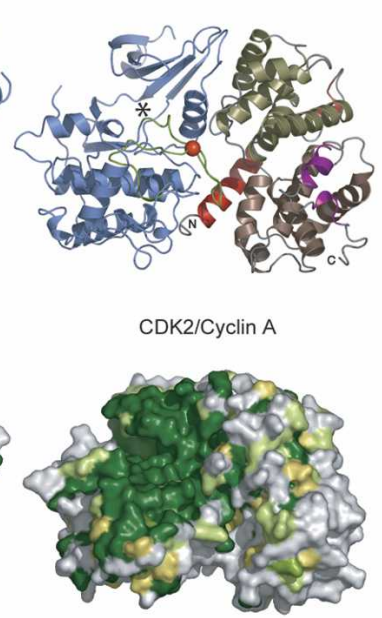

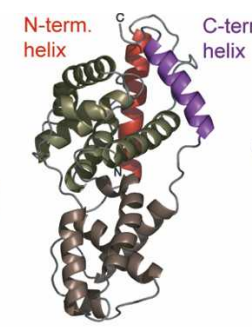

Cyclin $\mathrm{H}$

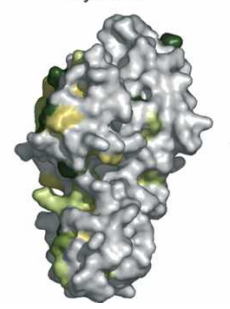

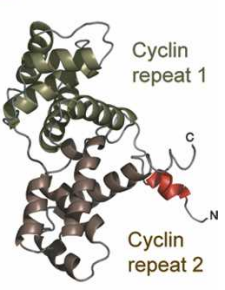

Cyclin C

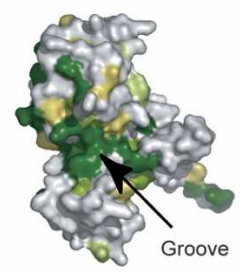

Figure 3. Structural information on CTD kinase/cyclin pairs. (A) Structures of CDK7 (Lolli et al. 2004), the CDK2/cyclin A pair (Russo et al. 1996), cyclin $\mathrm{H}$ (Andersen et al. 1997), and cyclin C (S. Hoeppner, S. Baumli, and P. Cramer, unpubl.) (from left to right). Kinases are in blue, with the activation segment in green and the phosphorylated residue highlighted with a red sphere. The active site is indicated with a star. Cyclin repeats 1 and 2 are colored in olive and brown, respectively. The $\mathrm{N}$ - and $\mathrm{C}$-terminal helices of the cyclins are in red and magenta, respectively. (B) Surface representations of the structures in $A$. Surface residues are colored from dark green to yellow according to decreasing degree of conservation. ing helix in transcription cyclins may interact with other factors (Andersen et al. 1997; S. Hoeppner, S. Baumli, and P. Cramer, unpubl.). The N- and C-terminal helices of cyclin $\mathrm{H}$ adopt a different orientation compared to other known cyclin structures, and are required for structural integrity (Andersen et al. 1997). Cyclin C does not contain a C-terminal helix, and its $\mathrm{N}$-terminal helix has a different length and orientation as in other cyclins ( $\mathrm{S}$. Hoeppner, S. Baumli, and P. Cramer, unpubl.).

Models of CDK-cyclin pairs may be obtained by homology modeling with known CDK/cyclin complex structures, such as the human CDK2-cyclin A structure (Jeffrey et al. 1995; Russo et al. 1996). Such modeling identified highly conserved residues that are generally involved in CDK-cyclin interactions (Jeffrey et al. 1995; Andersen et al. 1997), and residues in the CDK-cyclin interface that are conserved only within a certain $\mathrm{CDK}$ or cyclin family (S. Hoeppner, S. Baumli, and P. Cramer, unpubl.). Theses "specific" residues may govern preferential interaction of a certain cyclin with a certain CDK. However, it remains very difficult to rationalize the basis for specific CDK-cyclin complex formation based on the available structures, because the detailed structure of the interface regions may change upon complex formation, and since additional protein subunits can contribute to specific kinase-cyclin assembly.

Despite the recent structural studies, the basis for specificity of a kinase for the CTD and for recognition of a particular CTD residue remains enigmatic, because no structures of CDK/CTD complexes are known. Compared with other CDK structures, the activation segment of CDK7 is in a different conformation, which may help in determining substrate specificity (Russo et al. 1996; Lolli et al. 2004). Compared with CDK7, CDK8 has three additional residues in the activation segment, and a nine-residue insertion near the activation segment, which could play a role in defining substrate specificity (S. Hoeppner, S. Baumli, and P. Cramer, unpubl.).

Kinase specificity for the CTD may not only be achieved by CTD recognition at the kinase active site, but also by CTD binding to kinase-associated factors. CDK7 specificity for the CTD is influenced by its binding to MAT1 (Yankulov and Bentley 1997; Larochelle et al. 1998), but it is unclear how MAT1 accomplishes this function, although the NMR structure of its RING finger domain is known (Gervais et al. 2001). The CDK7-containing CAK complex targets other CDKs, but TFIIH, which includes the CAK complex, has a strong preference for the CTD as a substrate (Rossignol et al. 1997; Yankulov and Bentley 1997). CDK7 CTD specificity is highest in the context of a transcription initiation complex (Lu et al. 1992; Watanabe et al. 2000), and the preference of TFIIH for S5 phosphorylation is enforced by TFIIE (Yamamoto et al. 2001). Cyclin C has a highly conserved surface depression that may bind substrates near the active site of CDK8 (S. Hoeppner, S. Baumli, and P. Cramer, unpubl.). A similar mechanism is established for cyclin A, which has a conserved surface patch that binds kinase substrates (Schulman et al. 1998; Kontopidis et al. 2003). Cyclin T binds the CTD via a histidinerich stretch in its C-terminal domain (Taube et al. 2002; Kurosu et al. 2004). A recent study suggests that the cyclins generally act as adaptors to render a CDK specific for a substrate (Loog and Morgan 2005). The HIV Tat protein shifts CDK9 phosphorylation preference from S2 to both S2 and S5 (Zhou et al. 2000). Noncanonical phosphorylation of the CTD at Y1 by the Abl kinase involves CTD binding to an Abl domain distinct from the kinase domain (Baskaran et al. 1997).

An open question is the activation mechanism of the CTD-targeting CDKs. CDKs involved in cell cycle regulation are generally activated in two steps, cyclin binding, and phosphorylation of a conserved threonine in the CDK activation segment (T160 in human CDK2) (Pavletich 1999/. Interaction of the phosphothreonine side chain with three conserved arginines triggers a conformational change that results in full kinase activation (Russo et al. 1996). CDK7 and CDK9 carry a threonine or a serine at the phosphorylated position. In the free CDK7 structure, the phosphorylated threonine, however, is found at a different location than in CDK2 (Lolli et al. 
2004), and does not contact the three conserved arginines, pointing to a different mechanism of CDK activation. Also, CDK8 does not have a threonine or serine residue at the position phosphorylated in other CDKs (Tassan et al. 1995). A conserved aspartate in CDK8 or a glutamate in cyclin $\mathrm{C}$ could, however, mimic a phosphothreonine (S. Hoeppner, S. Baumli, and P. Cramer, unpubl.).

\section{CTD phosphatases of the Fcp1 family}

Recycling of Pol II requires CTD dephosphorylation by Fcp1, a conserved and essential phosphatase that is globally required for gene expression (Chambers and Dahmus 1994; Chambers and Kane 1996; Archambault et al. 1997, 1998; Cho et al. 1999; Kobor et al. 1999; Lin et al. 2002b). Fcp1 dephosphorylates both the free CTD and transcription elongation complexes (Chambers et al. 1995; Cho et al. 1999; Lehman and Dahmus 2000; Kong et al. 2005). Fcp1 contains an $\mathrm{N}$-terminal catalytic region $(\mathrm{FCPH})$ that includes the $\mathrm{DXDX}(\mathrm{T} / \mathrm{V})$ signature motif of a superfamily of phosphotransferases and -hydrolases (Collet et al. 1998), and a C-terminal breast cancer protein related C-terminal (BRCT) domain, which binds to the phosphorylated CTD (Yu et al. 2003). In higher eukaryotes, small CTD phosphatases (SCPs) were described, which contain a catalytic FCPH domain, but lack a BRCT domain (Yeo et al. 2003). SCPs are transcriptional regulators that silence neuronal genes in nonneuronal tissue (Yeo et al. 2005). Plants contain CTD phosphatase-like proteins (CPLs), which also comprise a catalytic domain with a DXDXT motif, and also lack a BRCT domain (Koiwa et al. 2004).

The high-resolution structure of the catalytic FCPH domain of Scp1 (Kamenski et al. 2004) revealed a core fold with a central parallel $\beta$-sheet (Fig. 4; Kamenski et al. 2004). The fold is similar to that of other enzymes of the DXDX(T/V) superfamily (Wang et al. 2001; Lahiri et al. 2003), although they share no sequence similarity outside the signature motif. The signature motif is part of a central depression that forms the active site and binds a metal ion. Catalysis involves the metal-assisted phosphorylation of the first aspartate in the $\operatorname{DXDX}(\mathrm{T} / \mathrm{V})$ motif. Magnesium ions are essential for Fcp1 and Scp1 activity, and the trifluoroberyllate anion inhibits activity by forming a stable tetrahedral adduct with the catalytic aspartate side chain, mimicking a labile phosphoaspartyl intermediate (Fig. 4; Kamenski et al. 2004). This mechanism is consistent with biochemical data (Hausmann and Shuman 2003), and corresponds to that of other $\operatorname{DXDX}(\mathrm{T} / \mathrm{V})$ superfamily enzymes, which also use the $\mathrm{N}$-terminal aspartate in the signature motif as a phosphoryl acceptor (H. Cho et al. 2001; Lahiri et al. 2003). Consistently, mutation of this aspartate in Scp1 or Fcp1 to alanine abolished activity (Kobor et al. 1999; Hausmann and Shuman 2002; Kamenski et al. 2004). The second asparate in the $\operatorname{DXDX}(\mathrm{T} / \mathrm{V})$ motif contributes to metal ion binding, and may act as a general acid/ base.

Whereas the catalytic mechanism of Fcp1/Scp1 phos-
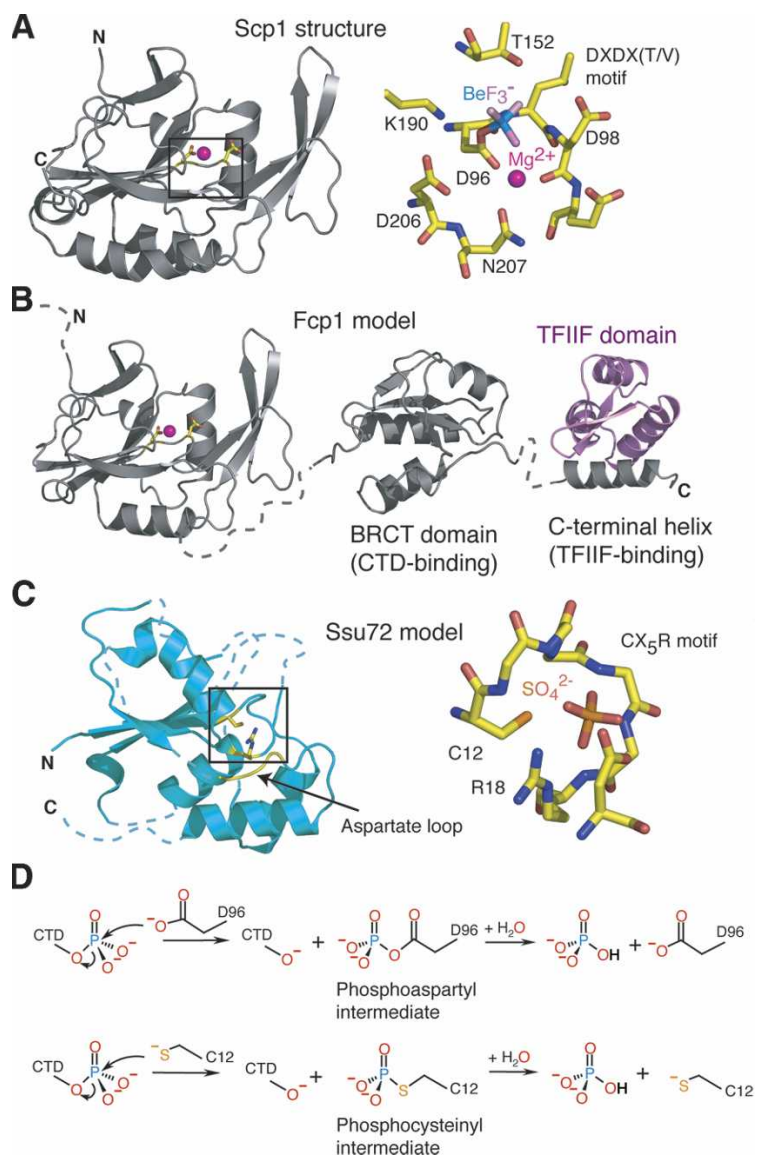

Figure 4. Structure and mechanism of CTD phosphatases. $(A)$ Scp1 structure and active site. The structure of Scp1 (Kamenski et al. 2004) is shown on the left as a ribbon model with two aspartate residues in the active site and a metal ion highlighted. The detailed view on the right depicts the active-site region (marked by a rectangle in the structure on the left). Depicted is a trifluoroberyllate ion, which binds the catalytic side chain of residue D96, resulting in a mimicry of a phosphoaspartyl intermediate. (B) Fcp1 model. The FCPH domain (left) was modeled based on the Scp1 structure (Kamenski et al. 2004). The BRCT domain was modeled based on PDB-IDlcdz (X. Zhang et al. 1998). The C-terminal Fcpl helix in complex with the TFIIF domain is taken from PDB-ID 1j2x (Kamada et al. 2003). (C) Ssu72 model. Ssu72 has been modeled by homology based on the structure of the bovine low-molecular-weight phosphotyrosine phosphatase (PDB-ID 1phr) (Su et al. 1994). Loop regions that are uncertain are shown as dashed lines. The detailed view on the right depicts the active-site region (marked by a rectangle in the structure on the left). A sulfate ion trapped in the structure is depicted in orange/red. The phosphorylated side chain of cysteine residue C12 is shown. (D) Proposed mechanisms of CTD phosphatases Scp1/Fcp1 (top) and Ssu72 (bottom). The reaction mechanisms involve the formation of a phosphoaspartyl (Scp1, Fcp1) or a phosphocysteinyl intermediate (Ssu72), followed by recycling of the catalytic side chain with the use of a nucleophilic water molecule.

phatases is well understood, the basis for their CTD specificity remains to be fully established. Specificity for the CTD may to some extent be explained by recruitment of the enzymes to the CTD. Fcp1 binds to a dock- 
ing site on Pol II outside the CTD (Chambers et al. 1995) that includes the Pol II subcomplex Rpb4/7 (Kimura et al. 2002; Kamenski et al. 2004). Rpb4/7 is located directly adjacent to the polymerase linker to the CTD (Armache et al. 2003; Bushnell and Kornberg 2003; Armache et al. 2005). In addition, Fcp1 binds the phosphorylated CTD via its BRCT domain (Yu et al. 2003), and binds the polymerase-associated general transcription factor TFIIF, which stimulates Fcp1 activity (Chambers et al. 1995; Archambault et al. 1998; Kamada et al. 2003; Nguyen et al. 2003).

Specificity of the CTD phosphatases toward CTD phosphorylation sites requires recognition of CTD residues around the phosphorylated target side chain. Indeed, Fcp1 activity requires several CTD residues flanking the phosphoserine, and single alanine mutations of the flanking Y1 and P3 decrease activity (Hausmann et al. 2004). Fcp1 and Scp1 were reported to dephosphorylate S5 and S2 (Hausmann and Shuman 2002; Lin et al. 2002a; Yeo et al. 2003). Highly purified Fcp1 was recently shown to dephosphorylate S5, but not S2 (Kong et al. 2005). Since both serines are flanked on the C-terminal side by a proline residue, CTD phosphatases may bind the adjacent prolines P3 or P6, and preferential phosphoserine dephosphorylation may be achieved by binding to other nearby residues. Indeed, the P3 side chain binds to a hydrophobic pocket in the known CTD peptide complex structures (Verdecia et al. 2000; Fabrega et al. 2003; Meinhart and Cramer 2004), and specific recognition of a flanking proline is consistent with Fcp1 inhibition by the prolyl isomerase Pin1 (Xu et al. 2003). Plant CPLs were also shown to specifically dephosphorylate S5 (Koiwa et al. 2004), and therefore most likely also recognize flanking residues.

\section{CTD phosphatase Ssu72}

The highly conserved and essential protein Ssu72 plays roles in all three phases of the transcription cycle. Ssu72 was originally identified in a yeast genetic screen as enhancer of a defect caused by a mutation in the initiation factor TFIIB (Sun and Hampsey 1996), and binds to TFIIB (Wu and Hampsey 1999; Pappas and Hampsey 2000; Dichtl et al. 2002a). Ssu72 is also involved in mRNA elongation, since its mutation can increase Pol II pausing and can counteract toxicity of the elongation inhibitor 6-azauracil (Dichtl et al. 2002a). Ssu72 is further involved in both poly(A)-dependent and -independent termination (Steinmetz and Brow 2003). It is a subunit of the yeast cleavage and polyadenylation factor $(\mathrm{CPF})$, which is part of the machinery for mRNA 3'-end formation. Finally, Ssu72 is also essential for transcription termination of snRNAs (Ganem et al. 2003).

Two groups independently reported that Ssu72 has phosphatase activity, and speculated that it may target the CTD (Ganem et al. 2003; Meinhart et al. 2003). Ssu72 cleaves a nonspecific phosphatase substrate, and its sequence contains the $\mathrm{CX}_{5} \mathrm{R}$ signature motif of protein tyrosine phosphatases (PTPases) (Ganem et al. 2003; Meinhart et al. 2003). Mutation of the cysteine in this signature motif abolishes Ssu72 activity in vitro (Meinhart et al. 2003), and confers lethality in vivo (Sun and Hampsey 1996). In PTPases, the conserved cysteine and arginine residues of the signature motif form part of the active site (Ramponi and Stefani 1997). Whereas the cysteine attacks the substrate phosphorus atom, leading to formation of a phosphocysteinyl intermediate, the arginine stabilizes the transition state (Burke and Zhang 1998). Although there is no apparent sequence homology between Ssu72 and PTPases outside the signature motif, secondary structure prediction suggested that Ssu72 adopts the fold of the low-molecular-weight family of PTPases (Fig. 4). In PTPases, an aspartate in a distant loop serves as a general acid/base (Barford et al. 1995; M. Zhang et al. 1998). Ssu72 may also contain such an aspartate loop, which is, however, 10 residues shorter than in low-molecular-weight PTPases, and comprises two catalytically important aspartates instead of one (Meinhart et al. 2003). This and other distinguishing features suggest that Ssu72 is the founding member of a new phosphatase subfamily that is related to low-molecularweight PTPases. Consistently, low-molecular-weight PTPases and Ssu72 are specifically inhibited by vanadate, which can mimic a pentavalent transition state.

It was recently found that Ssu 72 is, indeed, acting as a CTD phosphatase (Krishnamurthy et al. 2004). Depletion of Ssu72 in vivo results in an increase of S5-phosphorylated Pol II, and Ssu72 dephosphorylates recombinant CTD that had been phosphorylated at S5 by TFIIH in vitro. Ssu72 activity is associated with Ptal, another component of CPF. The essential role of Ssu72 in 3'processing does not, however, depend on its phosphatase activity. Mammalian Ssu72 was recently shown to also bind Ptal and Pol II (St-Pierre et al. 2005). The exact role of Ssu72, however, remains to be elucidated.

\section{Outlook}

Recent biochemical and structural studies provide insights into the mechanisms of CTD recognition and modification, but many questions remain. What other protein folds are involved in CTD recognition, and what is the structure of the CTD in complex with such proteins? How is indirect recognition of a CTD phosphate group accomplished? What are the determinants of CTD specificity of CTD kinases and phosphatases? How are some of these enzymes made processive? Is there a crosstalk between CTD kinases and phosphatases, and how is it achieved? How many copies of CTD-binding factors bind to the CTD at a given time? Do different factors bind to the CTD simultaneously, and how do they communicate? Answers to these questions can be expected from continued biochemical and structural studies of CTD-binding and -modifying proteins.

\section{Acknowledgments}

We thank R. Chapman, K. Sträßer, D. Eick, and members of the Cramer laboratory for comments. We apologize to those colleagues whose work could not be cited. 


\section{References}

Akoulitchev, S., Chuikov, S., and Reinberg, D. 2000. TFIIH is negatively regulated by cdk8-containing mediator complexes. Nature 407: 102-106.

Allen, M., Friedler, A., Schon, O., and Bycroft, M. 2002. The structure of an FF domain from human HYPA/FBP11. J. Mol. Biol. 323: 411-416.

Andersen, G., Busso, D., Poterszman, A., Hwang, J.R., Wurtz, J.-M., Ripp, R., Thierry, J.-C., Egly, J.-M., and Moras, D. 1997. The structure of cyclin $\mathrm{H}$ : Common mode of kinase activation and specific features. EMBO J. 16: 958-967.

Archambault, J., Chambers, R.S., Kobor, M.S., Ho, Y., Cartier, M., Bolotin, D., Andrews, B., Kane, C.M., and Greenblatt, J. 1997. An essential component of a C-terminal domain phosphatase that interacts with transcription factor IIF in Saccharomyces cerevisiae. Proc. Natl. Acad. Sci. 94: 1430014305.

Archambault, J., Pan, G., Dahmus, G.K., Cartier, M., Marshall, N., Zhang, S., Dahmus, M.E., and Greenblatt, J. 1998. FCP1, the RAP74-interacting subunit of a human protein phosphatase that dephosphorylates the carboxyl-terminal domain of RNA polymerase IIO. J. Biol. Chem. 273: 27593-27601.

Ares Jr., M. and Proudfoot, N.J. 2005. The Spanish connection: Transcription and mRNA processing get even closer. Cell 120: 163-166.

Armache, K.-J., Kettenberger, H., and Cramer, P. 2003. Architecture of the initiation-competent 12-subunit RNA polymerase II. Proc. Natl. Acad. Sci. 100: 6964-6968.

Armache, K.-J., Mitterweger, S., Meinhart, A., and Cramer, P. 2005. Structures of complete RNA polymerase II and its subcomplex Rpb4/7. J. Biol. Chem. 280: 7131-7134.

Asturias, F.J., Jiang, Y.W., Myers, L.C., Gustafsson, C.M., and Kornberg, R.D. 1999. Conserved structures of mediator and RNA polymerase II holoenzyme. Science 283: 985-987.

Barford, D., Jia, Z., and Tonks, N.K. 1995. Protein tyrosine phosphatases take off. Nat. Struct. Biol. 2: 1043-1053.

Barilla, D., Lee, B.A., and Proudfoot, N.J. 2001. Cleavage/polyadenylation factor IA associates with the carboxyl-terminal domain of RNA polymerase II in Saccharomyces cerevisiae. Proc. Natl. Acad. Sci. 98: 445-450.

Baskaran, R., Dahmus, M.E., and Wang, J.Y. 1993. Tyrosine phosphorylation of mammalian RNA polymerase II carboxyl-terminal domain. Proc. Natl. Acad. Sci. 90: 1116711171.

Baskaran, R., Chiang, G.G., Mysliwiec, T., Kruh, G.D., and Wang, J.Y. 1997. Tyrosine phosphorylation of RNA polymerase II carboxyl-terminal domain by the Abl-related gene product. J. Biol. Chem. 272: 18905-18909.

Baumli, S., Hoeppner, S., and Cramer, P. 2005. A conserved mediator hinge revealed in the structure of the MED7/ MED21 (Med7/Srb7) heterodimer. J. Biol. Chem. [Epub ahead of print February 14].

Bienkiewicz, E.A., Moon Woody, A., and Woody, R.W. 2000. Conformation of the RNA polymerase II C-terminal domain: Circular dichroism of long and short fragments. J. Mol. Biol. 297: 119-133.

Bjorklund, S. and Gustafsson, C.M. 2004. The mediator complex. Adv. Protein Chem. 67: 43-65.

Bonnet, F., Vigneron, M., Bensaude, O., and Dubois, M.F. 1999. Transcription-independent phosphorylation of the RNA polymerase II C-terminal domain (CTD) involves ERK kinases (MEK1/2). Nucleic Acids Res. 27: 4399-4404.

Borggrefe, T., Davis, R., Erdjument-Bromage, H., Tempst, P., and Kornberg, R.D. 2002. A complex of the Srb8, -9, -10, and -11 transcriptional regulatory proteins from yeast. J. Biol.
Chem. 277: 44202-44207.

Bork, P. and Sudol, M. 1994. The WW domain: A signalling site in dystrophin? Trends Biochem. Sci. 19: 531-533.

Boube, M., Joulia, L., Cribbs, D.L., and Bourbon, H.M. 2002. Evidence for a mediator of RNA polymerase II transcriptional regulation conserved from yeast to man. Cell 110: 143-151.

Bourbon, H.M., Aguilera, A., Ansari, A.Z., Asturias, F.J., Berk, A.J., Bjorklund, S., Blackwell, T.K., Borggrefe, T., Carey, M., Carlson, M., et al. 2004. A unified nomenclature for protein subunits of mediator complexes linking transcriptional regulators to RNA polymerase II. Mol. Cell 14: 553-557.

Bregman, D.B., Pestell, R.G., and Kidd, V.J. 2000. Cell cycle regulation and RNA polymerase II. Front. Biosci. 5: D244D257.

Buratowski, S. 2003. The CTD code. Nat. Struct. Biol. 10: 679680.

Burke Jr., T.R. and Zhang, Z.Y. 1998. Protein-tyrosine phosphatases: Structure, mechanism, and inhibitor discovery. Biopolymers 47: 225-241.

Bushnell, D.A. and Kornberg, R.D. 2003. Complete RNA polymerase II at 4.1 A resolution: Implications for the initiation of transcription. Proc. Nat1. Acad. Sci. 100: 6969-6972.

Cagas, P.M. and Corden, J.L. 1995. Structural studies of a synthetic peptide derived from the carboxyl-terminal domain of RNA polymerase II. Proteins 21: 149-160.

Carty, S.M., Goldstrohm, A.C., Sune, C., Garcia-Blanco, M.A., and Greenleaf, A.L. 2000. Protein-interaction modules that organize nuclear function: FF domains of CA150 bind the phosphoCTD of RNA polymerase II. Proc. Natl. Acad. Sci. 97: 9015-9020.

Chambers, R.S. and Dahmus, M.E. 1994. Purification and characterization of a phosphatase from HeLa cells which dephosphorylates the C-terminal domain of RNA polymerase II. J. Biol. Chem. 269: 26243-26248.

Chambers, R.S. and Kane, C.M. 1996. Purification and characterization of an RNA polymerase II phosphatase from yeast. J. Biol. Chem. 271: 24498-24504.

Chambers, R.S., Wang, B.Q., Burton, Z.F., and Dahmus, M.E. 1995. The activity of COOH-terminal domain phosphatase is regulated by a docking site on RNA polymerase II and by the general transcription factors IIF and IIB. J. Biol. Chem. 270: 14962-14969.

Chapman, R.D., Palancade, B., Lang, A., Bensaude, O., and Eick, D. 2004. The last CTD repeat of the mammalian RNA polymerase II large subunit is important for its stability. Nucleic Acids Res. 32: 35-44.

Chi, Y., Huddleston, M.J., Zhang, X., Young, R.A., Annan, R.S., Carr, S.A., and Deshaies, R.J. 2001. Negative regulation of Gen 4 and Msn 2 transcription factors by Srb10 cyclin-dependent kinase. Genes \& Dev. 15: 1078-1092.

Cho, E.J., Takagi, T., Moore, C.R., and Buratowski, S. 1997. mRNA capping enzyme is recruited to the transcription complex by phosphorylation of the RNA polymerase II carboxy-terminal domain. Genes \& Dev. 11: 3319-3326.

Cho, H., Kim, T.K., Mancebo, H., Lane, W.S., Flores, O., and Reinberg, D. 1999. A protein phosphatase functions to recycle RNA polymerase II. Genes \& Dev. 13: 1540-1552.

Cho, E.J., Kobor, M.S., Kim, M., Greenblatt, J., and Buratowski, S. 2001. Opposing effects of Ctk1 kinase and Fcp1 phosphatase at Ser 2 of the RNA polymerase II C-terminal domain. Genes \& Dev. 15: 3319-3329.

Cho, H., Wang, W., Kim, R., Yokota, H., Damo, S., Kim, S.H., Wemmer, D., Kustu, S., and Yan, D. 2001. BeF(3)(-) acts as a phosphate analog in proteins phosphorylated on aspartate: Structure of a $\operatorname{BeF}(3)(-)$ complex with phosphoserine phos- 
phatase. Proc. Natl. Acad. Sci. 98: 8525-8530.

Coin, F. and Egly, J.M. 1998. Ten years of TFIIH. Cold Spring Harb. Symp. Quant. Biol. 63: 105-110.

Collaborative Computational Project, Number 4. 1994. The CCP4 Suite: Programs for protein crystallography. Acta Cryst. D50: $760-763$.

Collet, J.F., Stroobant, V., Pirard, M., Delpierre, G., and Van Schaftingen, E. 1998. A new class of phosphotransferases phosphorylated on an aspartate residue in an amino-terminal DXDX(T/V) motif. J. Biol. Chem. 273: 14107-14112.

Corden, J.L., Cadena, D.L., Ahearn Jr., J.M., and Dahmus, M.E. 1985. A unique structure at the carboxyl terminus of the largest subunit of eukaryotic RNA polymerase II. Proc. Natl. Acad. Sci. 82: 7934-7938.

Cramer, P., Bushnell, D.A., and Kornberg, R.D. 2001. Structural basis of transcription: RNA polymerase II at 2.8 angstrom resolution. Science 292: 1863-1876.

Dahmus, M.E. 1995. Phosphorylation of the C-terminal domain of RNA polymerase II. Biochim. Biophys. Acta 1261: 171182.

Davis, J.A., Takagi, Y., Kornberg, R.D., and Asturias, F.A. 2002. Structure of the yeast RNA polymerase II holoenzyme: Mediator conformation and polymerase interaction. Mol. Cell 10: 409-415.

Dichtl, B., Blank, D., Ohnacker, M., Friedlein, A., Roeder, D., Langen, H., and Keller, W. 2002a. A role for SSU72 in balancing RNA polymerase II transcription elongation and termination. Mol. Cell 10: 1139-1150.

Dichtl, B., Blank, D., Sadowski, M., Hubner, W., Weiser, S., and Keller, W. 2002b. Yhhlp/Cftlp directly links poly(A) site recognition and RNA polymerase II transcription termination. EMBO J. 21: 4125-4135.

Dobbins, J.R., Murali, N., and Long, E.C. 1996. Structural redesign and stabilization of the overlapping tandem $\beta$-turns of RNA polymerase II. Int. J. Pept. Protein Res. 47: 260-268.

Dotson, M.R., Yuan, C.X., Roeder, R.G., Myers, L.C., Gustafsson, C.M., Jiang, Y.W., Li, Y., Kornberg, R.D., and Asturias, F.J. 2000. Structural organization of yeast and mammalian mediator complexes. Proc. Natl. Acad. Sci. 97: 1430714310.

Dubois, M.F., Vincent, M., Vigneron, M., Adamczewski, J., Egly, J.M., and Bensaude, O. 1997. Heat-shock inactivation of the TFIIH-associated kinase and change in the phosphorylation sites on the C-terminal domain of RNA polymerase II. Nucleic Acids Res. 25: 694-700.

Dynlacht, B.D. 1997. Regulation of transcription by proteins that control the cell cycle. Nature 389: 149-152.

Fabrega, C., Shen, V., Shuman, S., and Lima, C.D. 2003. Structure of an mRNA capping enzyme bound to the phosphorylated carboxy-terminal domain of RNA polymerase II. Mol. Cell 11: 1549-1561.

Fong, N., Bird, G., Vigneron, M., and Bentley, D.L. 2003. A 10 residue motif at the C-terminus of the RNA pol II CTD is required for transcription, splicing and $3^{\prime}$ end processing. EMBO T. 22: 4274-4282.

Ganem, C., Devaux, F., Torchet, C., Jacq, C., QuevillonCheruel, S., Labesse, G., Facca, C., and Faye, G. 2003. Ssu72 is a phosphatase essential for transcription termination of snoRNAs and specific mRNAs in yeast. EMBO J. 22: 15881598.

Gervais, V., Busso, D., Wasielewski, E., Poterszman, A., Egly, J.M., Thierry, J.C., and Kieffer, B. 2001. Solution structure of the N-terminal domain of the human TFIIH MAT1 subunit: New insights into the RING finger family. I. Biol. Chem. 276: 7457-7464.

Gu, W., Malik, S., Ito, M., Yuan, C.X., Fondell, J.D., Zhang, X.,
Martinez, E., Qin, J., and Roeder, R.G. 1999. A novel human SRB/MED-containing cofactor complex, SMCC, involved in transcription regulation. Mol. Cell 3: 97-108.

Guidi, B.W., Bjornsdottir, G., Hopkins, D.C., Lacomis, L., Erdjument-Bromage, H., Tempst, P., and Myers, L.C. 2004. Mutual targeting of mediator and the TFIIH kinase Kin28. J. Biol. Chem. 279: 29114-29120.

Guo, Z. and Stiller, J.W. 2004. Comparative genomics of cyclindependent kinases suggest co-evolution of the RNAP II Cterminal domain and CTD-directed CDKs. BMC Genomics 5: 69 .

Hallberg, M., Polozkov, G.V., Hu, G.Z., Beve, J., Gustafsson, C.M., Ronne, H., and Bjorklund, S. 2004. Site-specific Srb10dependent phosphorylation of the yeast Mediator subunit Med2 regulates gene expression from the 2-microm plasmid. Proc. Natl. Acad. Sci. 101: 3370-3375.

Harding, M.M. 1992. NMR studies on YSPTSPSY: Implications for the design of DNA bisintercalators. I. Med. Chem. 35: $4658-4664$.

Harper, J.W. and Elledge, S.J. 1998. The role of Cdk7 in CAK function, a retro-retrospective. Genes \& Dev. 12: 285-289.

Hausmann, S. and Shuman, S. 2002. Characterization of the CTD phosphatase Fcpl from fission yeast. Preferential dephosphorylation of serine 2 versus serine 5. J. Biol. Chem. 277: 21213-21220.

-2003. Defining the active site of Schizosaccharomyces pombe C-terminal domain phosphatase Fcp1. J. Biol. Chem. 278: 13627-13632.

Hausmann, S., Erdjument-Bromage, H., and Shuman, S. 2004. Schizosaccharomyces pombe carboxyl-terminal domain (CTD) phosphatase Fcp1: Distributive mechanism, minimal CTD substrate, and active site mapping. J. Biol. Chem. 279: 10892-10900.

Hengartner, C.J., Thompson, C.M., Zhang, J., Chao, D.M., Liao, S.-M., Koleske, A.J., Akamura, S., and Young, R.A. 1995. Association of an activator with an RNA polymerase II holoenzyme. Genes \& Dev. 9: 897-910.

Hengartner, C.J., Myer, V.E., Liao, S.-M., Wilson, C.J., Koh, S.S., and Young, R.A. 1998. Temporal regulation of RNA polymerase II by Srb10 and Kin28 cyclin-dependent kinases. Mol. Cell 2: 43-53.

Hirose, Y. and Manley, J.L. 1998. RNA polymerase II is an essential mRNA polyadenylation factor. Nature 395: 93-96.

- 2000. RNA polymerase II and the integration of nuclear events. Genes \& Dev. 14: 1415-1429.

Ho, C.K., Sriskanda, V., McCracken, S., Bentley, D., Schwer, B., and Shuman, S. 1998. The guanylyltransferase domain of mammalian mRNA capping enzyme binds to the phosphorylated carboxyl-terminal domain of RNA polymerase II. J. Biol. Chem. 273: 9577-9585.

Holstege, F.C.P., Jennings, E.G., Wyrick, J.J., Lee, T.I., Hengartner, C.J., Green, M.R., Golub, T.R., Lander, E.S., and Young, R.A. 1998. Dissecting the regulatory circuitry of a eukaryotic genome. Cell 95: 717-728.

Hu, D., Mayeda, A., Trembley, J.H., Lahti, J.M., and Kidd, V.J. 2003. CDK11 complexes promote pre-mRNA splicing. $J$. Biol. Chem. 278: 8623-8629.

Jeffrey, P.D., Russo, A.A., Polyak, K., Gibbs, E., Hurwitz, J., Massague, J., and Pavletich. N.P. 1995. Mechanism of CDK activation revealed by the structure of a cyclinA-CDK2 complex. Nature 376: 313-320.

Jiang, Y.W., Veschambre, P., Erdjument-Bromage, H., Tempst, P., Conaway, J.W., Conaway, R.C., and Kornberg, R.D. 1998. Mammalian mediator of transcriptional regulation and its possible role as an end-point of signal transduction pathways. Proc. Nat1. Acad. Sci. 95: 8538-8543. 
Jones, J.C., Phatnani, H.P., Haystead, T.A., MacDonald, J.A., Alam, S.M., and Greenleaf, A.L. 2004. C-terminal repeat domain kinase I phosphorylates Ser2 and Ser5 of RNA polymerase II C-terminal domain repeats. I. Biol. Chem. 279: 24957-24964.

Kaldis, P. 1999. The cdk-activating kinase (CAK): From yeast to mammals. Cell. Mol. Life Sci. 55: 284-296.

Kamada, K., Roeder, R.G., and Burley, S.K. 2003. Molecular mechanism of recruitment of TFIIF-associating RNA polymerase C-terminal domain phosphatase (FCP1) by transcription factor IIF. Proc. Natl. Acad. Sci. 100: 2296-2299.

Kamenski, T., Heilmeier, S., Meinhart, A., and Cramer, P. 2004. Structure and mechanism of RNA polymerase II CTD phosphatases. Mol. Cell 15: 399-407.

Kang, J.S., Kim, S.H., Hwang, M.S., Han, S.J., Lee, Y.C., and Kim, Y.J. 2001. The structural and functional organization of the yeast mediator complex. I. Biol. Chem. 276: 4200342010.

Kelly, W.G., Dahmus, M.E., and Hart, G.W. 1993. RNA polymerase II is a glycoprotein. Modification of the $\mathrm{COOH}$-terminal domain by O-GlcNAc. J. Biol. Chem. 268: 1041610424.

Keogh, M.C., Podolny, V., and Buratowski, S. 2003. Bur1 kinase is required for efficient transcription elongation by RNA polymerase II. Mol. Cell. Biol. 23: 7005-7018.

Kettenberger, H., Armache, K.-J., and Cramer, P. 2004. Complete RNA polymerase II elongation complex structure and its interactions with NTP and TFIIS. Mol. Cell 16: 955-965.

Kim, Y.K., Bourgeois, C.F., Isel, C., Churcher, M.J., and Karn, J. 2002. Phosphorylation of the RNA polymerase II carboxylterminal domain by CDK9 is directly responsible for human immunodeficiency virus type 1 Tat-activated transcriptional elongation. Mol. Cell. Biol. 22: 4622-4637.

Kim, M., Ahn, S.H., Krogan, N.J., Greenblatt, J.F., and Buratowski, S. 2004a. Transitions in RNA polymerase II elongation complexes at the 3' ends of genes. EMBO J. 23: 354-364.

Kim, M., Krogan, N.J., Vasiljeva, L., Rando, O.J., Nedea, E., Greenblatt, J.F., and Buratowski, S. 2004b. The yeast Rat1 exonuclease promotes transcription termination by RNA polymerase II. Nature 432: 517-522.

Kimura, M., Suzuki, H., and Ishihama, A. 2002. Formation of a carboxy-terminal domain phosphatase (Fcp1)/TFIIF/RNA polymerase II (pol II) complex in Schizosaccharomyces pombe involves direct interaction between Fcp1 and the Rpb4 subunit of pol II. Mol. Cell. Biol. 22: 1577-1588.

Kizer, K.O., Phatnani, H.P., Shibata, Y., Hall, H., Greenleaf, A.L., and Strahl, B.D. 2005. A novel domain in Set2 mediates RNA polymerase II interaction and couples histone H3 K36 methylation with transcript elongation. Mol. Cell. Biol. 25: 3305-3316.

Kobor, M.S., Archambault, J., Lester, W., Holstege, F.C., Gileadi, O., Jansma, D.B., Jennings, E.G., Kouyoumdjian, F., Davidson, A.R., Young, R.A., et al. 1999. An unusual eukaryotic protein phosphatase required for transcription by RNA polymerase II and CTD dephosphorylation in S. cerevisiae. Mol. Cell 4: 55-62.

Koiwa, H., Hausmann, S., Bang, W.Y., Ueda, A., Kondo, N., Hiraguri, A., Fukuhara, T., Bahk, J.D., Yun, D.J., Bressan, R.A., et al. 2004. Arabidopsis C-terminal domain phosphatase-like 1 and 2 are essential Ser-5-specific C-terminal domain phosphatases. Proc. Natl. Acad. Sci. 101: 1453914544.

Komarnitsky, P., Cho, E.J., and Buratowski, S. 2000. Different phosphorylated forms of RNA polymerase II and associated mRNA processing factors during transcription. Genes \& Dev. 14: 2452-2460.
Kong, S.E., Kobor, M.S., Krogan, N.J., Somesh, B.P., Sogaard, T.M., Greenblatt, J.F., and Svejstrup, J.Q. 2005. Interaction of Fcpl phosphatase with elongating RNA polymerase II holoenzyme, enzymatic mechanism of action, and genetic interaction with elongator. J. Biol. Chem. 280: 4299-4306.

Kontopidis, G., Andrews, M.J., McInnes, C., Cowan, A., Powers, H., Innes, L., Plater, A., Griffiths, G., Paterson, D., Zheleva, D.I., et al. 2003. Insights into cyclin groove recognition: Complex crystal structures and inhibitor design through ligand exchange. Structure (Camb) 11: 1537-1546.

Krishnamurthy, S., He, X., Reyes-Reyes, M., Moore, C., and Hampsey, M. 2004. Ssu72 is an RNA polymerase II CTD phosphatase. Mol. Cell 14: 387-394.

Kumaki, Y., Matsushima, N., Yoshida, H., Nitta, K., and Hikichi, K. 2001. Structure of the YSPTSPS repeat containing two SPXX motifs in the CTD of RNA polymerase II: NMR studies of cyclic model peptides reveal that the SPTS turn is more stable than SPSY in water. Biochim. Biophys. Acta 1548: 81-93.

Kurosu, T., Zhang, F., and Peterlin, B.M. 2004. Transcriptional activity and substrate recognition of cyclin $\mathrm{T} 2$ from $\mathrm{P}-\mathrm{TEFb}$. Gene 343: 173-179.

Lahiri, S.D., Zhang, G., Dunaway-Mariano, D., and Allen, K.N. 2003. The pentacovalent phosphorus intermediate of a phosphoryl transfer reaction. Science 299: 2067-2071.

Larochelle, S., Pandur, J., Fisher, R.P., Salz, H.K., and Suter, B. 1998. Cdk7 is essential for mitosis and for in vivo Cdk-activating kinase activity. Genes \& Dev. 12: 370-381.

Laskowski, R.A., MacArthur, M.W., Moss, D.S., and Thornton, J.M. 1993. PROCHECK: A program to check the stereochemical quality of protein structures. J. Appl. Cryst. 26: 283-291.

Laybourn, P.J. and Dahmus, M.E. 1989. Transcription-dependent structural changes in the C-terminal domain of mammalian RNA polymerase subunit IIa/o. I. Biol. Chem. 264: 6693-6698.

Lehman, A.L. and Dahmus, M.E. 2000. The sensitivity of RNA polymerase II in elongation complexes to C-terminal domain phosphatase. J. Biol. Chem. 275: 14923-14932.

Leopold, P. and O'Farrell, P.H. 1991. An evolutionarily conserved cyclin homolog from Drosophila rescues yeast deficient in G1 cyclins. Cell 66: 1207-1216.

Lew, D.J., Dulic, V., and Reed, S.I. 1991. Isolation of three novel human cyclins by rescue of $\mathrm{G} 1$ cyclin $(\mathrm{Cln})$ function in yeast. Cell 66: 1197-1206.

Li, Z., Li, H., Devasahayam, G., Gemmill, T., Chaturvedi, V., Hanes, S.D., and Van Roey, P. 2005. The structure of the Candida albicans Ess1 prolyl isomerase reveals a well-ordered linker that restricts domain mobility. Biochemistry 44: 6180-6189.

Licatalosi, D.D., Geiger, G., Minet, M., Schroeder, S., Cilli, K., McNeil, J.B., and Bentley, D.L. 2002. Functional interaction of yeast pre-mRNA $3^{\prime}$ end processing factors with RNA polymerase II. Mol. Cell 9: 1101-1111.

Lin, P.S., Dubois, M.F., and Dahmus, M.E. 2002a. TFIIF-associating carboxyl-terminal domain phosphatase dephosphorylates phosphoserines 2 and 5 of RNA polymerase II. J. Biol. Chem. 277: 45949-45956.

Lin, P.S., Marshall, N.F., and Dahmus, M.E. 2002b. CTD phosphatase: Role in RNA polymerase II cycling and the regulation of transcript elongation. Prog. Nucleic Acid Res. Mol. Biol. 72: 333-365.

Liu, Y., Ranish, J.A., Aebersold, R., and Hahn, S. 2001. Yeast nuclear extract contains two major forms of RNA polymerase II mediator complexes. J. Biol. Chem. 276: 7169-7175.

Liu, Y., Kung, C., Fishburn, J., Ansari, A.Z., Shokat, K.M., and 
Hahn, S. 2004. Two cyclin-dependent kinases promote RNA polymerase II transcription and formation of the scaffold complex. Mol. Cell. Biol. 24: 1721-1735.

Lolli, G., Lowe, E.D., Brown, N.R., and Johnson, L.N. 2004. The crystal structure of human CDK7 and its protein recognition properties. Structure (Camb) 12: 2067-2079.

Loog, M. and Morgan, D.O. 2005. Cyclin specificity in the phosphorylation of cyclin-dependent kinase substrates. Nature 434: 104-108.

Lu, H., Zawel, L., Fisher, L., Egly, J.-M., and Reinberg, D. 1992. Human general transcription factor IIH phosphorylates the C-terminal domain of RNA polymerase II. Nature 358: 641645.

Malik, S. and Roeder, R.G. 2000. Transcriptional regulation through Mediator-like coactivators in yeast and metazoan cells. Trends Biochem. Sci. 25: 277-283.

Maniatis, T. and Reed, R. 2002. An extensive network of coupling among gene expression machines. Nature 416: 499506.

Marshall, N.F. and Price, D.H. 1995. Purification of P-TEFb, a transcription factor required for the transition into productive elongation. J. Biol. Chem. 270: 12335-12338.

Marshall, N.F., Peng, J., Xie, Z., and Price, D.H. 1996. Control of RNA polymerase II elongation potential by a novel carboxylterminal domain kinase. J. Biol. Chem. 271: 27176-27183.

Matsushima, N., Creutz, C.E., and Kretsinger, R.H. 1990. Polyproline, $\beta$-turn helices. Novel secondary structures proposed for the tandem repeats within rhodopsin, synaptophysin, synexin, gliadin, RNA polymerase II, hordein, and gluten. Proteins 7: 125-155.

McCracken, S., Fong, N., Rosonina, E., Yankulov, K., Brothers, G., Siderovski, D., Hessel, A., Foster, S., Shuman, S., and Bentley, D.L. 1997a. 5'-Capping enzymes are targeted to premRNA by binding to the phosphorylated carboxy-terminal domain of RNA polymerase II. Genes \& Dev. 11: 3306-3318.

McCracken, S., Fong, N., Yankulov, K., Ballantyne, S., Pan, G., Greenblatt, J., Patterson, S.D., Wickens, M., and Bentley, D.L. 1997b. The C-terminal domain of RNA polymerase II couples mRNA processing to transcription. Nature 385: 357-361.

Meinhart, A. and Cramer, P. 2004. Recognition of RNA polymerase II carboxy-terminal domain by 3'-RNA-processing factors. Nature 430: 223-226.

Meinhart, A., Silberzahn, T., and Cramer, P. 2003. The mRNA transcription/processing factor Ssu72 is a potential tyrosine phosphatase. J. Biol. Chem. 278: 15917-15921.

Meredith, G.D., Chang, W.H., Li, Y., Bushnell, D.A., Darst, S.A., and Kornberg, R.D. 1996. The C-terminal domain revealed in the structure of RNA polymerase II. J. Mol. Biol. 258: 413419.

Michels, A.A., Nguyen, V.T., Fraldi, A., Labas, V., Edwards, M., Bonnet, F., Lania, L., and Bensaude, O. 2003. MAQ1 and 7SK RNA interact with CDK9/cyclin T complexes in a transcription-dependent manner. Mol. Cell. Biol. 23: 4859-4869.

Morris, D.P. and Greenleaf, A.L. 2000. The splicing factor, Prp40, binds the phosphorylated carboxyl-terminal domain of RNA polymerase II. J. Biol. Chem. 275: 39935-39943.

Morris, D.P., Phatnani, H.P., and Greenleaf, A.L. 1999. Phospho-carboxyl-terminal domain binding and the role of a prolyl isomerase in pre-mRNA $3{ }^{\prime}$-end formation. J. Biol. Chem. 274: 31583-31587.

Murray, A.W. 2004. Recycling the cell cycle: Cyclins revisited. Cell 116: 221-234.

Murray, S., Udupa, R., Yao, S., Hartzog, G., and Prelich, G. 2001. Phosphorylation of the RNA polymerase II carboxy-terminal domain by the Burl cyclin-dependent kinase. Mol. Cell. Biol.
21: 4089-4096.

Myers, L.C. and Kornberg, R.D. 2000. Mediator of transcriptional regulation. Annu. Rev. Biochem. 69: 729-749.

Myers, L.C., Gustafsson, C.M., Bushnell, D.A., Lui, M., Erdjument-Bromage, H., Tempst, P., and Kornberg, R.D. 1998. The Med proteins of yeast and their function through the RNA polymerase II carboxy-terminal domain. Genes \& Dev. 12: $45-54$.

Myers, J.K., Morris, D.P., Greenleaf, A.L., and Oas, T.G. 2001. Phosphorylation of RNA polymerase II CTD fragments results in tight binding to the WW domain from the yeast prolyl isomerase Ess1. Biochemistry 40: 8479-8486.

Naar, A.M., Taatjes, D.J., Zhai, W., Nogales, E., and Tjian, R. 2002. Human CRSP interacts with RNA polymerase II CTD and adopts a specific CTD-bound conformation. Genes \& Dev. 16: 1339-1344.

Nelson, C., Goto, S., Lund, K., Hung, W., and Sadowski, I. 2003. Srb10/Cdk8 regulates yeast filamentous growth by phosphorylating the transcription factor Ste12. Nature 421: 187190.

Nguyen, V.T., Kiss, T., Michels, A.A., and Bensaude, O. 2001. 7SK small nuclear RNA binds to and inhibits the activity of CDK9/cyclin T complexes. Nature 414: 322-325.

Nguyen, B.D., Abbott, K.L., Potempa, K., Kobor, M.S., Archambault, J., Greenblatt, J., Legault, P., and Omichinski, J.G. 2003. NMR structure of a complex containing the TFIIF subunit RAP74 and the RNA polymerase II carboxyl-terminal domain phosphatase FCP1. Proc. Nat1. Acad. Sci. 100: 56885693.

Noble, C.G., Hollingworth, D., Martin, S.R., Ennis-Adeniran, V., Smerdon, S.J., Kelly, G., Taylor, I.A., and Ramos, A. 2005. Key features of the interaction between Pcf11 CID and RNA polymerase II CTD. Nat. Struct. Mol. Biol. 12: 144-151.

Nonet, M., Sweetser, D., and Young, R.A. 1987. Functional redundancy and structural polymorphism in the large subunit of RNA polymerase II. Cell 50: 909-915.

Palancade, B. and Bensaude, O. 2003. Investigating RNA polymerase II carboxyl-terminal domain (CTD) phosphorylation. Eur. J. Biochem. 270: 3859-3870.

Pappas Jr., D.L. and Hampsey, M. 2000. Functional interaction between Ssu72 and the Rpb2 subunit of RNA polymerase II in Saccharomyces cerevisiae. Mol. Cell. Biol. 20: 8343-8351.

Park, J.M., Gim, B.S., Kim, J.M., Yoon, J.H., Kim, H.S., Kang, J.G., and Kim, Y.J. 2001. Drosophila Mediator complex is broadly utilized by diverse gene-specific transcription factors at different types of core promoters. Mol. Cell. Biol. 21: 2312-2323.

Patturajan, M., Schulte, R.J., Sefton, B.M., Berezney, R., Vincent, M., Bensaude, O., Warren, S.L., and Corden, J.L. 1998a. Growth-related changes in phosphorylation of yeast RNA polymerase II. J. Biol. Chem. 273: 4689-4694.

Patturajan, M., Wei, X., Berezney, R., and Corden, J.L. 1998b. A nuclear matrix protein interacts with the phosphorylated Cterminal domain of RNA polymerase II. Mol. Cell. Biol. 18: $2406-2415$.

Pavletich, N.P. 1999. Mechanisms of cyclin-dependent kinase regulation: Structures of Cdks, their cyclin activators, and Cip and INK4 inhibitors. J. Mol. Biol. 287: 821-828.

Payne, J.M. and Dahmus, M.E. 1993. Partial purification and characterization of two distinct protein kinases that differentially phosphorylate the carboxyl-terminal domain of RNA polymerase subunit IIa. J. Biol. Chem. 268: 80-87.

Peng, J., Zhu, Y., Milton, J.T., and Price, D.H. 1998. Identification of multiple cyclin subunits of human P-TEFb. Genes \& Dev. 12: 755-762.

Phatnani, H.P., Jones, J.C., and Greenleaf, A.L. 2004. Expanding 
the functional repertoire of CTD kinase I and RNA polymerase II: Novel phosphoCTD-associating proteins in the yeast proteome. Biochemistry 43: 15702-15719.

Pinhero, R., Liaw, P., Bertens, K., and Yankulov, K. 2004. Three cyclin-dependent kinases preferentially phosphorylate different parts of the C-terminal domain of the large subunit of RNA polymerase II. Eur. J. Biochem. 271: 1004-1014.

Prelich, G. 2002. RNA polymerase II carboxy-terminal domain kinases: Emerging clues to their function. Eukaryot. Cell 1: 153-162.

Prelich, G. and Winston, F. 1993. Mutations that suppress the deletion of an upstream activating sequence in yeast: Involvement of a protein kinase and histone $\mathrm{H} 3$ in repressing transcription in vivo. Genetics 135: 665-676.

Price, D. 2000. P-TEFb, a cyclin-dependent kinase controlling elongation by RNA polymerase II. Mol. Cell. Biol. 20: 26292634.

Proudfoot, N. 2004. New perspectives on connecting messenger RNA 3' end formation to transcription. Curr. Opin. Cell Biol. 16: 272-278.

Proudfoot, N.J., Furger, A., and Dye, M.J. 2002. Integrating mRNA processing with transcription. Cell 108: 501-512.

Ramanathan, Y., Reza, S.M., Young, T.M., Mathews, M.B., and Pe'ery, T. 1999. Human and rodent transcription elongation factor P-TEFb: Interactions with human immunodeficiency virus type 1 tat and carboxy-terminal domain substrate. $J$. Virol. 73: 5448-5458.

Ramanathan, Y., Rajpara, S.M., Reza, S.M., Lees, E., Shuman, S., Mathews, M.B., and Pe'ery, T. 2001. Three RNA polymerase II carboxyl-terminal domain kinases display distinct substrate preferences. J. Biol. Chem. 276: 10913-10920.

Ramponi, G. and Stefani, M. 1997. Structure and function of the low Mr phosphotyrosine protein phosphatases. Biochim. Biophys. Acta 1341: 137-156.

Ranganathan, R., Lu, K.P., Hunter, T., and Noel, J.P. 1997. Structural and functional analysis of the mitotic rotamase Pin1 suggests substrate recognition is phosphorylation dependent. Cell 89: 875-886.

Reed, R. 2003. Coupling transcription, splicing and mRNA export. Curr. Opin. Cell Biol. 15: 326-331.

Rickert, P., Seghezzi, W., Shanahan, F., Cho, H., and Lees, E. 1996. Cyclin C/CDK8 is a novel CTD kinase associated with RNA polymerase II. Oncogene 12: 2631-2640.

Rickert, P., Corden, J.L., and Lees, E. 1999. Cyclin C/CDK8 and cyclin $\mathrm{H} / \mathrm{CDK} 7 / \mathrm{p} 36$ are biochemically distinct CTD kinases. Oncogene 18: 1093-1102.

Rodriguez, C.R., Cho, E.J., Keogh, M.C., Moore, C.L., Greenleaf, A.L., and Buratowski, S. 2000. Kin28, the TFIIH-associated carboxy-terminal domain kinase, facilitates the recruitment of mRNA processing machinery to RNA polymerase II. Mol. Cell. Biol. 20: 104-112.

Rossignol, M., Kolb-Cheynel, I., and Egly, J.M. 1997. Substrate specificity of the cdk-activating kinase (CAK) is altered upon association with TFIIH. EMBO J. 16: 1628-1637.

Russo, A.A., Jeffrey, P.D., and Pavletich, N.P. 1996. Structural basis of cyclin-dependent kinase activation by phosphorylation. Nat. Struct. Biol. 3: 696-700.

Sadowski, M., Dichtl, B., Hubner, W., and Keller, W. 2003. Independent functions of yeast Pcf11p in pre-mRNA $3^{\prime}$ end processing and in transcription termination. EMBO J. 22: 2167-2177.

Samuelsen, C.O., Baraznenok, V., Khorosjutina, O., Spahr, H., Kieselbach, T., Holmberg, S., and Gustafsson, C.M. 2003. TRAP230/ARC240 and TRAP240/ARC250 Mediator subunits are functionally conserved through evolution. Proc. Nat1. Acad. Sci. 100: 6422-6427.
Schroeder, S.C., Schwer, B., Shuman, S., and Bentley, D. 2000. Dynamic association of capping enzymes with transcribing RNA polymerase II. Genes \& Dev. 14: 2435-2440.

Schulman, B.A., Lindstrom, D.L., and Harlow, E. 1998. Substrate recruitment to cyclin-dependent kinase 2 by a multipurpose docking site on cyclin A. Proc. Natl. Acad. Sci. 95: 10453-10458.

Schultz, P., Fribourg, S., Poterszman, A., Mallouh, V., Moras, D., and Egly, J.M. 2000. Molecular structure of human TFIIH. Cell 102: 599-607.

Shim, E.Y., Walker, A.K., Shi, Y., and Blackwell, T.K. 2002. CDK-9/cyclin $\mathrm{T}(\mathrm{P}-\mathrm{TEFb})$ is required in two postinitiation pathways for transcription in the C. elegans embryo. Genes \& Dev. 16: 2135-2146.

Sims III, R.J., Mandal, S.S., and Reinberg, D. 2004. Recent highlights of RNA-polymerase-II-mediated transcription. Curr. Opin. Cell Biol. 16: 263-271.

Steinmetz, E.J. and Brow, D.A. 2003. Ssu72 protein mediates both poly(A)-coupled and poly(A)-independent termination of RNA polymerase II transcription. Mol. Cell. Biol. 23: 6339-6349.

Steinmetz, E.J., Conrad, N.K., Brow, D.A., and Corden, J.L. 2001. RNA-binding protein Nrd1 directs poly(A)-independent 3 '-end formation of RNA polymerase II transcripts. $\mathrm{Na}$ ture 413: 327-331.

Stiller, J.W. and Cook, M.S. 2004. Functional unit of the RNA polymerase II C-terminal domain lies within heptapeptide pairs. Eukaryot. Cell 3: 735-740.

St-Pierre, B., Liu, X., Kha, L.C., Zhu, X., Ryan, O., Jiang, Z., and Zacksenhaus, E. 2005. Conserved and specific functions of mammalian ssu72. Nucleic Acids Res. 33: 464-477.

Su, X.D., Taddei, N., Stefani, M., Ramponi, G., and Nordlund, P. 1994. The crystal structure of a low-molecular-weight phosphotyrosine protein phosphatase. Nature 370: 575-578.

Sun, Z.-W. and Hampsey, M. 1996. Synthetic enhancement of a TFIB defect by a mutation in SSU72, an essential yeast gene encoding a novel protein that affects transcription start site selection in vivo. Mol. Cell. Biol. 16: 1557-1566.

Sun, X., Zhang, Y., Cho, H., Rickert, P., Lees, E., Lane, W., and Reinberg, D. 1998. NAT, a human complex containing Srb polypeptides that functions as a negative regulator of activated transcription. Mol. Cell 2: 213-222.

Suzuki, M. 1989. SPXX, a frequent sequence motif in gene regulatory proteins. J. Mol. Biol. 207: 61-84.

- 1990. The heptad repeat in the largest subunit of RNA polymerase II binds by intercalating into DNA. Nature 344: 562-565.

Svejstrup, J.Q., Li, Y., Fellows, J., Gnatt, A., Bjorklund, S., and Kornberg, R.D. 1997. Evidence for a mediator cycle at the initiation of transcription. Proc. Natl. Acad. Sci. 94: 60756078.

Taatjes, D.J., Naar, A.M., Andel III, F., Nogales, E., and Tjian, R. 2002. Structure, function, and activator-induced conformations of the CRSP coactivator. Science 295: 1058-1062.

Tarricone, C., Dhavan, R., Peng, J., Areces, L.B., Tsai, L.H., and Musacchio, A. 2001. Structure and regulation of the CDK5p25(nck5a) complex. Mol. Cell 8: 657-669.

Tassan, J.P., Schultz, S.J., Bartek, J., and Nigg, E.A. 1994. Cell cycle analysis of the activity, subcellular localization, and subunit composition of human CAK (CDK-activating kinase). J. Cell Biol. 127: 467-478.

Tassan, J.P., Jaquenoud, M., Leopold, P., Schultz, S.J., and Nigg, E.A. 1995. Identification of human cyclin-dependent kinase 8, a putative protein kinase partner for cyclin C. Proc. Natl. Acad. Sci. 92: 8871-8875.

Taube, R., Lin, X., Irwin, D., Fujinaga, K., and Peterlin, B.M. 
2002. Interaction between P-TEFb and the C-terminal domain of RNA polymerase II activates transcriptional elongation from sites upstream or downstream of target genes. Mol. Cell. Biol. 22: 321-331.

Thompson, C.M., Koleske, A.J., Chao, D.M., and Young, R.A. 1993. A multisubunit complex associated with the RNA polymerase II CTD and TATA-binding protein in yeast. Cell 73: $1361-1375$.

Trigon, S., Serizawa, H., Conaway, J.W., Conaway, R.C., Jackson, S.P., and Morange, M. 1998. Characterization of the residues phosphorylated in vitro by different C-terminal domain kinases. J. Biol. Chem. 273: 6769-6775.

Valay, J.-G., Simon, M., Dubois, M.-F., Bensaude, O., Facca, C., and Faye, G. 1995. The KIN28 gene is required both for RNA polymerase II mediated transcription and phosphorylation of the Rpb1 CTD. J. Mol. Biol. 249: 535-544.

Verdecia, M.A., Bowman, M.E., Lu, K.P., Hunter, T., and Noel, J.P. 2000. Structural basis for phosphoserine-proline recognition by group IV WW domains. Nat. Struct. Biol. 7: 639643.

Vincent, O., Kuchin, S., Hong, S.P., Townley, R., Vyas, V.K., and Carlson, M. 2001. Interaction of the Srb10 kinase with Sip4, a transcriptional activator of gluconeogenic genes in Saccharomyces cerevisiae. Mol. Cell. Biol. 21: 5790-5796.

Wada, T., Takagi, T., Yamaguchi, Y., Watanabe, D., and Handa, H. 1998. Evidence that P-TEFb alleviates the negative effect of DSIF on RNA polymerase II-dependent transcription in vitro. EMBO J. 17: 7395-7403.

Wang, W., Kim, R., Jancarik, J., Yokota, H., and Kim, S.H. 2001. Crystal structure of phosphoserine phosphatase from Methanococcus jannaschii, a hyperthermophile, at $1.8 \AA$ resolution. Structure (Camb) 9: 65-71.

Watanabe, Y., Fujimoto, H., Watanabe, T., Maekawa, T., Masutani, C., Hanaoka, F., and Ohkuma, Y. 2000. Modulation of TFIIH-associated kinase activity by complex formation and its relationship with CTD phosphorylation of RNA polymerase II. Genes Cells 5: 407-423.

West, M.L. and Corden, J.L. 1995. Construction and analysis of yeast RNA polymerase II CTD deletion and substitution mutations. Genetics 140: 1223-1233.

Wu, W.H. and Hampsey, M. 1999. An activation-specific role for transcription factor TFIIB in vivo. Proc. Natl. Acad. Sci. 96: 2764-2769

Xu, Y.X., Hirose, Y., Zhou, X.Z., Lu, K.P., and Manley, J.L. 2003. Pin 1 modulates the structure and function of human RNA polymerase II. Genes \& Dev. 17: 2765-2776.

Yamaguchi, Y., Wada, T., and Handa, H. 1998. Interplay between positive and negative elongation factors: Drawing a new view of DRB. Genes Cells 3: 9-15.

Yamamoto, S., Watanabe, Y., van der Spek, P.J., Watanabe, T., Fujimoto, H., Hanaoka, F., and Ohkuma, Y. 2001. Studies of nematode TFIIE function reveal a link between Ser-5 phosphorylation of RNA polymerase II and the transition from transcription initiation to elongation. Mol. Cell. Biol. 21: 115.

Yang, Z., Zhu, Q., Luo, K., and Zhou, Q. 2001. The 7SK small nuclear RNA inhibits the CDK9/cyclin T1 kinase to control transcription. Nature 414: 317-322.

Yankulov, K.Y. and Bentley, D.L. 1997. Regulation of CDK7 substrate specificity by MAT1 and TFIIH. EMBO J. 16: 1638-1646.

Yao, S. and Prelich, G. 2002. Activation of the Bur1-Bur2 cyclindependent kinase complex by Cak1. Mol. Cell. Biol. 22: 6750-6758.

Yao, S., Neiman, A., and Prelich, G. 2000. BUR1 and BUR2 encode a divergent cyclin-dependent kinase-cyclin complex important for transcription in vivo. Mol. Cell. Biol. 20: 7080-7087.

Yeo, M., Lin, P.S., Dahmus, M.E., and Gill, G.N. 2003. A novel RNA polymerase II C-terminal domain phosphatase that preferentially dephosphorylates serine 5. J. Biol. Chem. 278: 26078-26085.

Yeo, M., Lee, S.K., Lee, B., Ruiz, E.C., Pfaff, S.L., and Gill, G.N. 2005. Small CTD phosphatases function in silencing neuronal gene expression. Science 307: 596-600.

Yik, J.H., Chen, R., Nishimura, R., Jennings, J.L., Link, A.J., and Zhou, Q. 2003. Inhibition of P-TEFb (CDK9/cyclin T) kinase and RNA polymerase II transcription by the coordinated actions of HEXIM1 and 7SK snRNA. Mol. Cell 12: 971-982.

Yu, X., Chini, C.C., He, M., Mer, G., and Chen, J. 2003. The BRCT domain is a phospho-protein binding domain. Science 302: 639-642.

Yuryev, A. and Corden, J.L. 1996. Suppression analysis reveals a functional difference between the serines in positions two and five in the consensus sequence of the $\mathrm{C}$-terminal domain of yeast RNA polymerase II. Genetics 143: 661-671.

Yuryev, A., Patturajan, M., Litingtung, Y., Joshi, R.V., Gentile, C., Gebara, M., and Corden, J.L. 1996. The C-terminal domain of the largest subunit of RNA polymerase II interacts with a novel set of serine/arginine-rich proteins. Proc. Natl. Acad. Sci. 93: 6975-6980.

Zhang, J. and Corden, J.L. 1991. Phosphorylation causes a conformational change in the carboxyl-terminal domain of the mouse RNA polymerase II largest subunit. J. Biol. Chem. 266: 2297-2302.

Zhang, M., Stauffacher, C.V., Lin, D., and Van Etten, R.L. 1998. Crystal structure of a human low molecular weight phosphotyrosyl phosphatase. Implications for substrate specificity. J. Biol. Chem. 273: 21714-21720.

Zhang, X., Morera, S., Bates, P.A., Whitehead, P.C., Coffer, A.I., Hainbucher, K., Nash, R.A., Sternberg, M.J., Lindahl, T., and Freemont, P.S. 1998. Structure of an XRCC1 BRCT domain: A new protein-protein interaction module. EMBO J. 17: 6404-6411.

Zhou, M., Halanski, M.A., Radonovich, M.F., Kashanchi, F., Peng, J., Price, D.H., and Brady, J.N. 2000. Tat modifies the activity of CDK9 to phosphorylate serine 5 of the RNA polymerase II carboxyl-terminal domain during human immunodeficiency virus type 1 transcription. Mol. Cell. Biol. 20: 5077-5086.

Zorio, D.A. and Bentley, D.L. 2004. The link between mRNA processing and transcription: Communication works both ways. Exp. Cell Res. 296: 91-97. 


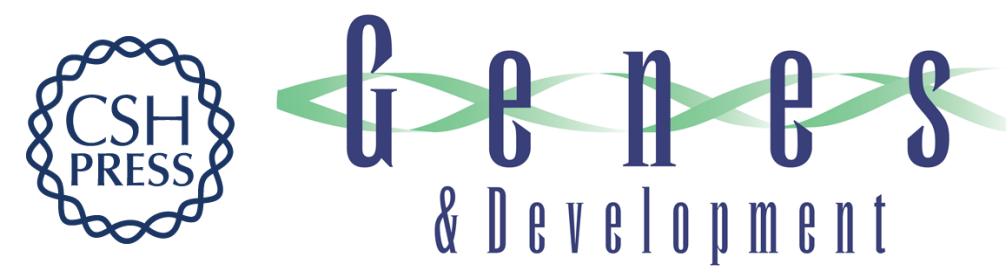

\section{A structural perspective of CTD function}

Anton Meinhart, Tomislav Kamenski, Sabine Hoeppner, et al.

Genes Dev. 2005, 19:

Access the most recent version at doi:10.1101/gad.1318105

References This article cites 203 articles, 113 of which can be accessed free at: http://genesdev.cshlp.org/content/19/12/1401.full.html\#ref-list-1

License

Email Alerting Receive free email alerts when new articles cite this article - sign up in the box at the top Service right corner of the article or click here.

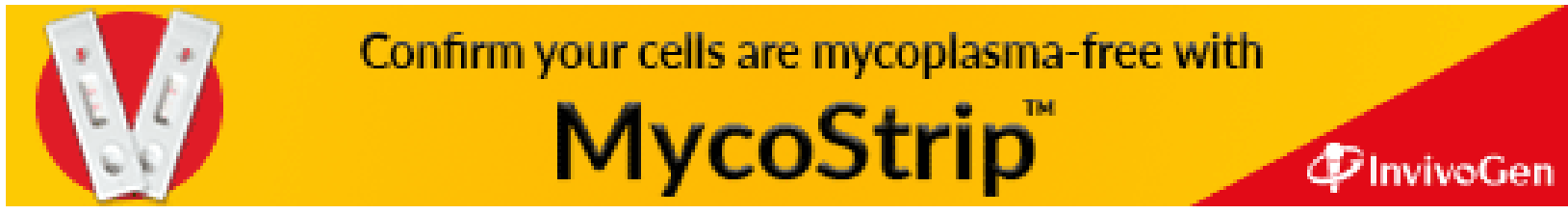

